\title{
Lift and Shift: The Effect of Fundraising I nterventions in Charity Space and Time
}

\author{
Kimberley Scharf \\ Sarah Smith \\ Mark Ottoni-Wilhelm
}

Discussion Paper 17 / 687

22 September 2017

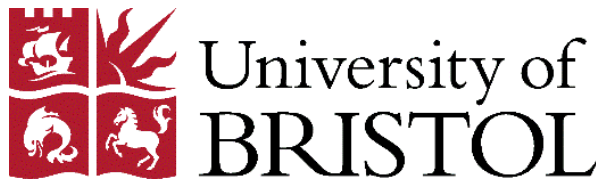

Department of Economics

University of Bristol

Priory Road Complex

Bristol BS8 1TU

United Kingdom 


\title{
Lift and Shift: The Effect of Fundraising Interventions in Charity Space and
}

\section{Time}

Kimberley Scharf (University of Birmingham)

Sarah Smith (University of Bristol)

Mark Ottoni-Wilhelm (IUPUI and IU Lilly Family School of Philanthropy)

\begin{abstract}
Fundraising interventions may lift donations and/or shift their composition and timing, making it important to study their effect across charity space and time. We find that major fundraising appeals lift total donations, but surprisingly shift donations to other charities across time. To explain this, we develop a two-period model with two sources of warm glow that relates donation responses to underlying preference parameters. A dynamic framework, combined with rich data, provides opportunities to identify substitutability/complementarity in warm glow. The observed pattern is possible only if the two sources of warm glow are substitutes and warm glow is intertemporally substitutable.
\end{abstract}

Keywords: Warm glow; donations; substitution; intertemporal substitution.

JEL codes: H41, D12, D64

\footnotetext{
* We are grateful to the Charities Aid Foundation and particularly to Susan Pinkney for making the data available. We have received helpful comments on earlier versions at numerous seminars, workshops and conferences. The authors declare that they have no relevant or material interests that relate to the research described in this paper.

Contact information

k.scharf@,bham.ac.uk (Scharf), sarah.smith@,bristol.ac.uk (Smith; corresponding author), mowilhel@iupui.edu (Ottoni-Wilhelm).
} 


\section{Introduction}

The provision of public goods requires intervention to reduce to free-riding. A large literature in economics has studied how different fundraising interventions can mitigate free-riding and increase donations. ${ }^{1}$ This literature typically focuses only on how much is raised by the charity doing the fundraising. However, it is important to take into account not only how much is raised by the fundraising charity at the time of the intervention, but also what happens to donations received by other charities and by the fundraising charity at a later point in time-because what enters the social welfare calculation is the overall level and mix of different types of public goods provided (Andreoni and Payne, 2013). The social welfare implications of a fundraising intervention that lifts total donations may be different compared to an intervention that shifts donations from other charities or from the future. The importance of the "lift/shift" question has been recognized since the early economic literature on fundraising (Rose-Ackerman, 1982), but remains unresolved (List, 2014) because addressing it places daunting requirements on the data.

This paper is the first to address the lift/shift question using data on donations to charity uniquely strong in the two dimensions necessary to provide a satisfying answer. The first dimension is charity space - the data must include donations to a comprehensive set of charities. The second is time - the data must be at a high enough frequency, and over a sufficiently long duration, to capture time-shifting behavior across the comprehensive set of charities. ${ }^{2}$

\footnotetext{
${ }^{1}$ Among the fundraising interventions shown to be effective are door-to-door fundraising (Landry et al., 2006, 2010; DellaVigna, List, and Malmendier, 2012; Andreoni, Rao, and Trachtman, 2017), lotteries (Morgan, 2000; Morgan and Sefton, 2000; Lange et al., 2007; Carpenter and Matthews, 2017) match subsidies (Karlan and List, 2007; Eckel and Grossman, 2008), lead donations (Huck and Rasul, 2011), gifts (Falk, 2007; Alpizar et al., 2008), social information (Meier, 2007; Shang and Croson, 2009), recognition (Harbaugh, 1998). For reviews, see Andreoni and Payne (2013), List (2011). ${ }^{2}$ Previous empirical investigations satisfactorily addressing the time dimension have had a lowdimensional charity-space of one to five different charities (Falk, 2007; Meier, 2007; van Diepen et al., 2009; Lange and Stocking, 2012; Donkers et al., 2017), or considered multiple donor-funded projects having similar purpose (Meer, 2017). The Panel Study of Income Dynamics allows comprehensive measurement of the charity-space, but the data are low-frequency in the time dimension and timeshifting/shifting between charities that occurs at frequencies faster than biennially cannot be detected (Reinstein, 2011; Brown et al., 2015). Bekkers' (2015) and Deryugina and Marx's (2015) data are also low-frequency in the time dimension. Other studies have been based on single point-in-time investigations of a low-dimensional (e.g., two or three) charity-space (Cairns and Slonim, 2011); Krieg and Samek (2017); Klar and Piston, 2015; Harwell and Eckel, 2015; Ek, 2017; Filiz-Ozbay and Uler, 2017).
} 
The new data we use are administrative records from donor accounts for more than 100,000 donors, recording donations to 80,000 charities on a day-by-day basis over the period June 2009 through July 2014. These data capture donations over a comprehensive set of all charities, allowing us to detect any shift in composition. We also measure donations at a high enough frequency, and for long enough after the fundraising intervention, to capture any time-shifting behavior. Our main focus is on six major appeals launched during the period by the UK Disasters Emergency Committee (DEC) in response to natural disasters and humanitarian crises. DEC is a charitable umbrella organisation of thirteen large international charities who coordinate relief, including a combined appeal for donations. Its appeals are nationwide in scope, and represent a set of plausibly exogenous, large-scale fundraising interventions. We also study the observed donation responses to major annual fundraising telethons in case it is thought that disaster appeals are atypical fundraising interventions.

Figure 1 tells the main story of the response to disaster appeals, showing the estimated average response in log donations, week-by-week, for the two weeks before the launch of an appeal through 20 weeks after (Section 3 presents full estimation details). Donations to DEC and its thirteen member charities (large international relief charities; "DEC-13") are in Panel a. The figure shows a large increase in donations to $D E C-13$ during the immediate aftermath of an appeal, followed in weeks 5-14 by an adjustment and settling back to baseline. Weeks 15-19 confirm that the baseline has been re-established. Appeals increase donations to $D E C-13$ over the entire 20-week period, and there is no indication of any time-shifting.

Donations to all other charities are in Panel $b$. The results are surprising. During the immediate aftermath, donations to other charities increase relative to their baseline level. Then the immediate increase is offset by lower-than-baseline donations during the adjustment and settling periods. Hence, the fundraising appeal by DEC time-shifts donations, not to $D E C-13$, but rather to other charities.

However, when summed over the entire 20 -week period, donations to other charities are unchanged. There is no evidence of an overall shift in donations to $D E C$ 13 from other charities. This result, in combination with the increased donations to $D E C-13$, means that the appeal lifts total donations. In response to major annual fundraising telethons we also find a lift in non-telethon donations in the immediate aftermath, and over the entire response period a lift in total donations. 
The second contribution of our paper is to develop a model with two sources of warm glow across two time periods that we use to map our empirical findings to underlying warm glow preferences. The model's comparative statics indicate that lift/shift patterns in donations do not map one-to-one to substitution/complementarity in underlying preferences. The reason is that any lift in total donations to the two charities that are the sources of warm glow, obscures identification of substitution/complementarity between the two warm glows. The analysis makes clear that whether or not underlying substitution/complementarity between the warm glows can be identified from donation responses to fundraising appeals depends on three magnitudes relative to each other: the underlying substitution/complementarity, the lift in total donations, and intertemporal substitution in warm glow. Having data rich in the time dimension, combined with our identification framework, allows us to draw two conclusions. First, warm glow is intertemporally substitutable. Second, the warm glow from donating to $D E C-13$ is a substitute for the warm glow from donating to the other charities.

The results are significant for several reasons. First, the main substantive finding is that major fundraising interventions lift total donations. This has implications for understanding the effect of fundraising on the level and mix of public goods provided. It also suggests that heated concern that major campaigns succeed at the expense of donations to other charities is exaggerated (e.g., Bernstein, 2005; MacAskill, 2014; Riley, 2014). Second, on a conceptual level, both the empirical and theoretical analyses highlight the importance of using a dynamic perspective to study the effect of fundraising. Had we conducted a static analysis focusing on the immediate aftermath of the appeal, we would have overstated the lift in total donations because donations to other charities had not yet fallen below baseline. Moreover, we would have had no clear conclusions about warm glow substitutability between charities, nor over time. Third, the dynamic framework provides new insights into the identification of warm glow preferences by showing how identification is bounded by the interplay between the underlying preference parameters. For example, the framework indicates that (under mild conditions) for a dynamic analysis to identify underlying warm glow substitutes when a static analysis cannot, it is necessary that the intertemporal substitution in warm glow exceed the lift in total donations. However, "too much" intertemporal substitution can re-obscure the underlying substitution between warm glows. Fourth, applying this framework to the 
empirical results allows us to draw specific conclusions about underlying warm glow preferences. These conclusions are the first to our knowledge that warm glow is substitutable both between charities and across time.

The plan of the rest of the paper is as follows. We discuss the data and empirical strategy in the next section and present the empirical results in Section 3. The theoretical framework and the mapping between observed donations and underlying preferences are discussed in Section 4. Section 5 concludes with a discussion of conceptual, research design, and practical implications.

\section{Empirical Approach}

\section{A. Data}

The data are anonymized records from donor accounts administered by the Charities' Aid Foundation (CAF). ${ }^{3}$ The accounts are dedicated checking accounts for making donations to charities. Anyone can set up an account with a minimum $£ 100$ one-off payment or $£ 10$ monthly direct debit; they can make additional contributions at any time, but cannot withdraw funds. Account holders can use available funds to make donations directly out of their account. Donations can be made to any registered charity and can be made in a variety of ways, including online, by phone or check. Further information on the accounts is provided in Appendix A.

We observe all donations made via the accounts over the period June 2009 July 2014. 107,559 individuals make at least one donation over the period. In total, 4.5 million donations are made to more than 80,000 charities. The mean (median) donation size is $£ 99$ ( $£ 25$ ). The mean (median) number of donations per donor per year is 14.9 (7), while the mean (median) value of total donations per donor per year is $£ 1,478$ ( $£ 450$ ). For each donation, the data contain the amount donated, the charity receiving the money, and the exact date. This data richness in both charity-space and time is the innovation that enables a satisfying answer to the lift/shift question.

\footnotetext{
3 The data were accessed on a secure CAF server with all information regarding name, address, ID details, telephone number and town/city removed by CAF prior to being made available thus ensuring complete anonymity. One of the benefits of a CAF account is the anonymity provided to individuals. Therefore, we only use data that are fully anonymised and cannot identify individuals. All the results reported in the paper are based on aggregated data, implying that no individual behavior can be identified.
} 
It is important during the interpretation of our results to keep in mind who the population of CAF donors represents. In short, the population of CAF donors represent people who do a large amount of charitable giving. As we explain in Appendix A, the advantages of setting up a CAF account, compared to making donations out of a regular checking account, are that a CAF account makes it easier to obtain the tax benefits of donating under the UK Gift Aid system, helps manage one's giving, and serves as a commitment device. These advantages would be expected to be more important to people who do a large amount of giving. Appendix A presents evidence confirming this by comparing donations made by CAF account holders to donations made by donors in a random sample drawn from the UK population: Just over half of CAF account holders are in the top decile of UK donors, just over 70 percent are in the top two deciles, and more than 70 percent of total donations in the UK are given by the top two deciles. Hence, by studying the CAF population we are studying lift/shift behavior among the type of donors who account for a high proportion of aggregate giving.

\section{B. DEC appeals}

Our analysis focuses on the six appeals launched by DEC during the period June 2009 - July 2014. These are described in Table 1; they include appeals in response to both natural disasters and humanitarian crises. For convenience, we use the term "disaster" to refer to both situations. Smith et al. (2017) provide more information on DEC and other disaster appeals.

The appeals have several features that make them well-suited for addressing the lift/shift question. First, they are large-scale fundraising interventions. A decision by DEC to launch an appeal triggers the Rapid Response Network. The Network includes broadcasters who produce appeal packages which go out on national television and radio. The Network also includes commercial banks, the Post Office, and telecommunication companies who work together to facilitate the collection of donations in person, online and by phone. The appeals generate a sizeable increase in donations to one charitable purpose (DEC and its member charities) that should be large enough to detect any lift/shift behavior.

Second, the disasters occur overseas, rather than within the UK. In the case of domestic disasters, there may be wider within-country effects caused by the disaster 
that impact donations, through channels other than the fundraising appeals. These include changes in levels of social cohesion and pro-sociality (De Alessi, 1975; Solnit, 2009; Rao et al., 2011) and religiosity (Bentzen, 2015) as well as effects on economic conditions and government spending (Fidrmuc et al., 2015).

Third, the appeals were launched at different times of the calendar year. This allows us to use an identification strategy that relies on variation in the timing of disaster appeals to identify responses in donations. Specifically, because the appeals occur at different times of the year, we can use flexible controls for systematic time effects. We make an identifying assumption that any remaining unobserved timevarying factors that might cause donations to change around the time of an appeal are averaged out across the six appeals.

Finally, all but one of the appeals occurred with a gap of several months between one and the next. This allows the data to determine empirically the end of the response period following an appeal, during which any shift pattern plays out, rather than our a priori imposing the end of the period. DEC appeals are actively promoted for a two-week period, but left open for up to six months. In practice, the data indicate that the response to the appeal ends between weeks $10-14$.

\section{Estimation}

We estimate the following empirical specification:

$$
\begin{aligned}
& \log \left(s_{t}\right)=a^{s}+\Sigma_{n=-2}^{N} \beta_{n}^{s} W_{n}+v_{t}^{s}+u_{t}^{s} \\
& \log \left(r_{t}\right)=a^{r}+\Sigma_{n=-2}^{N} \beta_{n}{ }_{n} W_{n}+v_{t}^{r}+u_{t}^{r}
\end{aligned}
$$

where $s_{t}$ is the sum of donations made by all donors to $D E C-13$ on day $t$, and $r_{t}$ is the donation sum to all Other charities. The key variables of interest are the set of weekly indicators $\left\{W_{n}\right\}^{N}{ }_{n=-2}$ defined relative to the date of the appeal, where week zero $\left(W_{0}\right)$ is the first seven-day period following the start of the appeal. The sets of coefficients on these indicators in the respective equations, $\left\{\beta_{n}^{s}\right\}_{n=-2}^{N}$ and $\left\{\beta_{n}^{r}\right\}^{N}{ }_{n=-2}$, capture average changes in donations during each week beginning with the start of the appeal and lasting an additional $N$ weeks $(n=0,1, \ldots, N)$. We also include indicators for the two weeks prior to the date of the appeal $(n=-2,-1)$ to test for any pre-existing 
trends in donations, as well as any response to the actual disaster that pre-dates the appeal. Hence, the "response periods" are the $N+3$ week periods surrounding the starts of the six appeals. The changes captured by the $\beta^{s}{ }_{n}$ and $\beta^{r}$ are relative to donations outside the response periods - the "baseline" periods.

Estimating this specification on daily data allows us to control flexibly for other systematic time effects, denoted $v_{t}^{s}$ and $v_{t}^{r}$ in (1), that include a linear trend and indicators for day of week, day of month, month, and separate indicators for public holidays and for the weeks after the two annual nationwide telethons that take place in the UK. The constant terms and error terms are $a^{s}, a^{r}$ and $u_{t}^{s}, u_{t}^{r}$, respectively.

Figure 2 illustrates the timing of response periods (in grey) and the baseline periods (in white). The figure presents residuals from a regression of log total donations, that is $d_{t}=s_{t}+r_{t}$, on all the systematic time controls, but excluding the set of indicators $\left\{W_{n}\right\}^{N}{ }_{n=-2}$ in order to highlight the underlying response to appeals. There is considerable variation in the residuals, even after including systematic time controls, but the appeals are clearly visible and are associated with a distinctive pattern in donations. First, the appeals are associated with large spikes in donations: Of the five biggest spikes over the period, four occur after DEC appeals. Second, the spikes following the appeals are persistent; the non-disaster spike (in December 2010) is quickly reversed. Third, the spikes following the appeals are followed by a period in which donations appear to be below their baseline level. We present evidence in the next section that this decrease is the result of time-shifting in Other donations.

We define the length of the response periods to be twenty weeks after the launch of an appeal $(N=19$ in (1)). Because our analysis assumes that the appeals affect donations during the response periods, but not during the baseline periods, the twenty-week definition is an identifying assumption. Three pieces of evidence support this assumption (details are in Appendix B). First, we extend the definition of the response period beyond the 20th week and find no evidence of any significant response in donations during the extended period. Second, donations return to the same level during the baseline periods that follow each of the disasters, even though the magnitude of the response to the disasters varies considerably, i.e. donations are the same level 20 weeks after the Haiti appeal as they are 20 weeks after the Syria appeal, even though the amounts raised were more than three times greater. This suggests that modelling the response to the appeals, during a twenty-week period 
following the launch, as a deviation from baseline is appropriate. Third, serial correlation in the residuals from the specification with a twenty-week response period is rejected. Evidence of serial correlation would have suggested that a twenty-week response period was not sufficiently long to model the dynamic response. In short, the evidence indicates that a twenty-week response period is long enough to capture any behavioral responses following the appeals, and that donations during the baseline periods are an appropriate reference point.

The absence of serial correlation in the residuals also indicates that OLS standard errors are consistent. As a second check we estimate specifications with data aggregated to the week, five-week, and twenty-week levels, and there are no substantive changes in the results (Appendix B).

\section{Empirical Results}

\section{A. Main results}

The pattern of coefficients and standard errors, plotted in Figure 1, indicates distinct periods in the response to appeals. During the immediate aftermath of the appeal (weeks $0-4$ ) there is a strong increase in donations to $D E C-13$ and also an increase in donations to other charities. During the adjustment (weeks $5-9$ ) donations to $D E C-13$ are lower than during the immediate aftermath but remain well above their baseline level. Also, donations to Other charities fall below their baseline level, reversing their increase in weeks $0-4$. In the settling period (weeks $10-14$ ) donations to DEC-13 and Other charities return to baseline levels. Weeks 15 - 19 mark the return to baseline: the effect of the appeal has played out.

Guided by this pattern of results, Table 2 summarizes the average response to the appeal during each of the four distinct periods - Aftermath, Adjustment, Settling and Return - as well as over the entire 20 -week period. The average responses are based on the specification as given by (1) estimated on daily data that includes indicators for the twenty weeks after each of the appeals. The responses during the different periods presented in Table 2 are defined by the average of the coefficients over the relevant weeks. The motivation for focusing on this smaller number of estimates is that it 
makes it easier to explore the key pattern of response and to compare across different specifications. The full week-by-week results are reported in Appendix B. ${ }^{4}$

The first row of Table 2 summarizes the average responses in donations to $D E C-13$. Column 1 indicates that in the five-week aftermath period, donations to $D E C-13$ are 381 per cent higher per week $\left(e^{1.571}-1=3.81\right)$ than they are in the baseline periods. In the adjustment and settling periods, the .429 and .112 estimates indicate that donations to $D E C-13$ gradually converge back to their baseline level over the two periods, but remain significantly higher than their baseline level in each period. That donations have returned to baseline is confirmed by the small $(0.035)$ insignificant coefficient in weeks $15-19$. There is no period in which donations to $D E C-13$ fall below baseline. Although there are large increases in donations to $D E C$ 13 in the weeks following the appeal, there is no evidence of subsequent offsetting reductions that would indicate time-shifting in donations. The average of the coefficients over the twenty-week response period is 0.537 , indicating that donations to $D E C-13$ are about 70 per cent $\left(e^{537}-1=.71\right)$ higher per week during the entire response period compared to baseline.

The second row of Table 2 summarizes responses in donations to all Other charities over the same periods. The results show a significant increase- 10 per cent relative to baseline - in donations to other charities during the immediate aftermath of the disaster appeal. This increase is subsequently reversed; donations are significantly lower than their baseline level during the adjustment period. This indicates timeshifting from the adjustment period to the immediate aftermath in donations to Other charities.

From the perspective of the entire twenty-week response period, the appeal has no overall effect on Other donations (the -0.008 coefficient is essentially zero) and the hypothesis that the increase in donations to $D E C-13$ comes entirely at the expense of Other donations (which would imply a 4.5 per cent drop to Other) can be rejected $(p<0.01)$. Panel $b$ provides confirmation that the appeal lifts total donations: The average coefficient over weeks $0-19$ indicates that total donations are almost 7 per cent higher in the response period compared to baseline.

\footnotetext{
4 The two pre-appeal weekly indicators are not displayed in Table 2, but are small (.092 and .202) and insignificant. An indicator marking the exact date of the disaster is also insignificant. These results confirm earlier findings that it is the appeals, not the disasters themselves, that are important in triggering donations responses (Stromberg and Eisensee, 2007).
} 
Appendix B presents results indicating that the pattern is not driven by a single appeal but is broadly similar across all appeals, and that the responses are driven by changes in the number of donations, as well as by changes in the average size of individual donations.

\section{B. Further analysis of the DEC appeals}

The main results indicate that in response to the DEC appeal, donors give more to $D E C-13$ with no later reduction, and at the same time give more to Other charities for whom there is no fundraising appeal, but that this increase to Other is subsequently offset with later reductions. In this section we test the robustness of these findings. First, we vary the definition of Other charities to exclude charities that might provide disaster relief. Second, we confirm that the observed patterns in donations to Other charities are driven by the same donors who respond to the disaster appeal.

A possible explanation for our findings is that the focus on donations to only DEC and the thirteen member charities masks a shift in donations to disaster relief from other charities that we would see with a broader definition of all the charities that may be involved in disaster relief. To test this, we split the group of Other donations into "other international" (i.e. charities classified as international, excluding DEC and its member organisations) and "non-international" (i.e. all other charities). ${ }^{5}$ The results for these two categories are presented in Table 3, Panel a. As might be expected, there is an increase in donations to "other international" during the aftermath period. But there is also an increase in donations to "non-international"; the behavioral pattern presented above for Other donations remains when we focus on "non-international". As a second check, Row 3 in Panel a selects ten of the largest UK-based charities that are unambiguously not involved in disaster relief, such as Cancer Research UK, and confirms the same pattern among this group.

Table 3, Panel $\mathrm{b}$ repeats the analysis for narrower categories within noninternational - religious, health, social services, education, environment and other.

\footnotetext{
${ }^{5}$ We use the classification provided by the National Council of Voluntary Organisations who assign a category from the International Classification of Non-Profit Organisations (ICNPO) to each registered charity based on their main (self-reported) activity. International is defined as "organizations promoting greater intercultural understanding between peoples of different countries and historical backgrounds and also those providing relief during emergencies and promoting development and welfare abroad". For further information on ICNPO categories see Salamon and Anheier (1996).
} 
The results show a common increase in donations during the aftermath period across all categories, that is greatest (and statistically significant) for health, social services and other. Donations are typically below baseline during the adjustment period and, to a lesser extent, the settling period, with statistically significant effects for religious giving, health and other. However, considering these disaggregated categories across the entire twenty-week response period, some differences emerge. Specifically, there is evidence of a shift away from donations to health, which are significantly lower during the response period than at baseline. The estimated coefficient indicates that donations to health charities are five per cent lower across the response period compared to baseline. This suggests that the degree of shifting in donations across charities may vary, depending on their purpose. We return to this in the next Section.

Another alternative explanation for the increase in Other donations in the immediate aftermath of an appeal is that it is a response to increased marketing activity by the other charities, rather than a direct response to the DEC appeal. To test this, Table 3, Panel c splits donors into two groups - "disaster donors" (62 per cent of the sample) who donate to $D E C-13$ at least once during any of the response periods, and "non-disaster donors" who never give to any of the appeals. Our assumption is that marketing activity by other charities would cause an increase in Other donations among all donors, while a direct behavioral response to the DEC appeal would imply an increase in Other donations only among those who give to disaster relief. The results indicate an increase in Other donations only among the donors who respond to disaster appeals. Similar results obtain if we split between "international donors" and "non-international donors". These results work against an explanation of marketing by other charities.

. The same evidence works against an explanation that the increase in Other donations occurs because the DEC appeal increases the salience of giving to all charities, even those not involved in disaster relief. If the salience explanation were valid, the increase in Other donations would obtain for the non-disaster donors, but the Panel $\mathrm{c}$ results indicate that it does not.

\section{Telethons}

This section addresses the question whether the observed pattern is unique to disaster appeals by looking at responses to the two largest, annual fundraising telethon appeals in the UK, run by BBC Children in Need and Comic/Sports Relief. BBC Children in 
Need raises money to help disadvantaged children and young people in the UK. Comic Relief/Sports Relief raises money to combat poverty and disadvantage in the UK and Africa. Both appeals feature one-night telethons that raise $£ 50$ - $£ 100$ million, an amount similar to most DEC appeals. Both appeals occur annually, at a regularly scheduled time of the year. Such telethons differ from DEC appeals primarily in that they aim to raise awareness of an on-going need, rather than draw attention to a dramatic increase in that need.

The estimation strategy is the same as above (specification 1), although we focus on a shorter response period of ten weeks (informed by the data), and drop the twenty-week response periods following the DEC appeals. Figure 3 plots the estimated coefficients on the indicators for the weeks before/after the dates of the appeals for donations to "telethons" and donations to "other" charities. Table 4 presents the average of the weekly coefficients corresponding to the five-week aftermath and adjustment periods.

The results indicate that telethon appeals lift total donations. There is an increase in donations to the telethon charities in the aftermath period, lasting for six weeks. The focus of the fundraising appeal is the one-night telethon, but the effect on donations persists for some time after this. There is some indication of time-shifting in donations to the "telethon" charities from the adjustment period, with negative coefficients in weeks $6-9$ but these are not significant, and not enough to offset the initial increase. As was the case with the DEC appeals, donations to other charities also increase in the aftermath period, but in this case, there is no evidence of timeshifting. Instead the results show that telethons increase donations both to the charities running the appeal and to all other charities. As with the earlier results on the effect of DEC appeals for health charities, these results indicate that the degree of shifting (in this case over time) may vary for different charities.

\section{Interpreting the response pattern: A dynamic, two warm glow model}

To be convincing, a model of donor behavior must be able to explain the lift in total donations and also the time-shifting in donations to Other charities. As discussed above, increased salience caused by the DEC appeal is not consistent with the fact that the increase in Other is driven by disaster donors. A plausible alternative candidate explanation are transactions costs. Previous studies have found that ex post 
transactions costs are of first order importance in stopping individuals from implementing their donation choices (Huck and Rasul, 2010; Meer and Rigbi, 2014). If DEC appeals lead individuals to donate to disaster relief, the act of giving to one charity seems likely to reduce the transactions costs of making donations to other charities at the same time. Donors may therefore bring forward donations to other charities they were intending to make at a later date.

Although intuitively plausible, this explanation is not supported by the evidence. First, if the transactions costs story were true, we would expect to see greater bunching of donations to $D E C-13$ and other charities during the aftermath period, i.e. donations to both $D E C-13$ and other charities being made on the same day. This is not the case. During the aftermath period, 27.5 per cent of donors donate to both DEC-13 and other charities at any time during the five weeks, of which 42.0 per cent do so on the same day. This is lower than the bunching that occurs at other times when an average of 52.2 per cent of donors who give to both $D E C-13$ and other during any five-week period do so on the same day. Second is the fact that there is an increase in the mean donation size to other charities during the aftermath (see Table B6, Appendix B) - the transactions costs story would suggest changes only on the extensive margin. Third is the fact that the shift patterns vary across different subcategories of other charities - for example, there is a shift to $D E C-13$ from health, but not from other sub-categories, while, in the case of telethon appeals, there is no timeshifting in other donations. There is no reason to expect transactions costs to result in this type of variation depending on which other charities are being considered.

We therefore present a new model of warm glow characteristics that can account parsimoniously for the observed responses. ${ }^{6}$ We introduce the model by means of a single-charity, single-period version, before extending to two-charities and two-periods to allow for shift in charity space and time. The presentation below focuses on the key points in the development of the model. A more detailed development of the model, the derivation of the comparative statics and the proofs of propositions are available on request.

\footnotetext{
${ }^{6}$ Cornes and Sandler (1984) introduced the idea of a warm glow characteristic.
} 
A warm glow characteristic, $\omega_{s}$, is the argument in a person's utility function that derives from her/his own donation:

$$
\omega_{s}=\alpha_{s} s
$$

where $s$ represents donations to charity $S$ (e.g. $D E C$-13). The parameter $\alpha_{s}$ represents the effectiveness with which donations $s$ in pounds to $S$ produce warm glow $\omega_{s}$. For example, a person living in relative comfort in the UK may feel guilty that others are struggling in poor countries, and a donation to charity $S$ can alleviate that guilt in proportion to $\alpha_{s}$. Or, a person may think it is her duty to help people in need, and donation to $S$ fulfils that duty, again in proportion to $\alpha_{s}$. Compared to previous warm glow models that have defined a term in utility, say $u(s)$, directly over the donations $s$ so that $\alpha_{s} \equiv 1$ in (2), it may seem like we are adding something new by modelling $\alpha_{s} \neq$ 1 , but we are not. Previous models have had the marginal utility of warm glow $u^{\prime}(s)$. In the characteristics model the parameter $\alpha_{s}$ is a construct that facilitates explicit analysis of the marginal utility of donations in producing warm glow.

Consider quasilinear utility defined over own consumption $c$ and warm glow $\omega_{s}:$

$$
U\left(c, \omega_{s}\right)=c+\theta \omega_{s}{ }^{\eta}
$$

where $0<\eta<1$ and $\theta>0$ are preference parameters. The budget constraint $c+s=$ $y$ can be rewritten in terms of the warm glow characteristic:

$$
c+\left(1 / \alpha_{s}\right) \omega_{s}=y \text {. }
$$

Define the hedonic price of warm glow as $p_{s} \equiv 1 / \alpha_{s}$ where the units of $p_{s}$ are pounds required to be donated to achieve one unit of warm glow. We model a fundraising appeal as an increase in the effectiveness with which donations to charity $S$ produce warm glow. Equivalently, a fundraising appeal reduces the price $p_{s}$ in terms of foregone $c$ necessary to achieve a unit of warm glow. In the case of DEC appeals, the dramatic increase in need linked to the disaster lies behind the fall in price. However, more generally, it is plausible that appeals themselves may change the price - the response to telethon appeals is consistent with this. 
The characteristics approach facilitates analysis by enabling well-known price theoretic results to be applied to the investigation of fundraising effectiveness. The optimal level of the warm glow characteristic is:

$$
\omega_{s}^{*}=\kappa p_{s}^{1 /(\eta-1)}
$$

where $\kappa \equiv(1 / \eta \theta)^{1 /(\eta-1)}$ is a constant and $\gamma \equiv 1 /(\eta-1)$ is the price elasticity of $\omega_{s}$.

Note that $\eta>0$ (the marginal utility of warm glow is positive) implies $\gamma<-1$ : the warm glow characteristic is price elastic. In other words, for a fundraising appeal that increases $\alpha_{s}$-effectiveness $\left(\downarrow p_{s}\right)$ to cause an increase in donations $s$ - that is, an increase in expenditures $p_{s} \omega_{s}=s$ on the warm glow characteristic $\omega_{s}$-it is necessary for the characteristic to be price elastic.

Next introduce a second warm glow characteristic that derives from donations, $r$, to a second charity $R$, which in our case would be all other, non-DEC charities:

$$
\omega_{r}=\alpha_{r} r .
$$

Allowing the second warm glow characteristic to have its own effectiveness parameter $\alpha_{r} \neq \alpha_{s}$ allows donations to different charities to be associated with different levels of utility. This is necessary to model the well-known stylized fact that different charities receive different portions of total donations.

To incorporate the second warm glow characteristic into the model, define a warm glow characteristic $g$ as the CES aggregation:

$$
g=\left(1 / 2 \omega_{s}^{\mu}+1 / 2 \omega_{r}^{\mu}\right)^{1 / \mu}
$$

where $\sigma=1 /(1-\mu)$ is the elasticity of substitution between the characteristics and use $g$ as a replacement for " $\omega_{s}$ " in (3):

$$
U(c, g)=c+\theta g^{\eta}
$$


The budget constraint is now:

$$
c+p_{s} \omega_{s}+p_{r} \omega_{r}=y \text {. }
$$

The effective price of aggregate warm glow $g$ is:

$$
p_{g}=\left(p_{s}^{1-\sigma}+p_{s}^{1-\sigma}\right)^{1 /(1-\sigma)}
$$

(see Diewert, 2014). Optimal $g^{*}=\kappa p_{g}{ }^{1 /(\eta-1)}$ as in (5) (with $p_{g}$ replacing $p_{s}$ ), and total donations to charities $S$ and $R$ combined are:

$$
d^{*}=g^{*}\left(p_{s}^{1-\sigma}+p_{s}^{1-\sigma}\right)^{1 /(1-\sigma)} \text {. }
$$

Donations to the respective charities are:

$$
\begin{aligned}
& s^{*}=d^{*} \phi \\
& r^{*}=d^{*}(1-\phi)
\end{aligned}
$$

where

$$
\phi=\frac{p_{s^{1-\sigma}}}{p_{s}^{1-\sigma}+p_{r}{ }^{1-\sigma}}
$$

is the share of total donations $d^{*}$ spent on charity $S$. Note that $\phi\left(\alpha_{s}, \alpha_{r}, \sigma\right)$ is a function of the two effectiveness parameters and the elasticity of substitution.

The effects of a fundraising appeal can be analysed using the comparative statics of (10) and (11). A fundraising appeal by one charity $S-\uparrow \alpha_{s}$, equivalently $\downarrow$ $p_{s}$ - has two effects. First, it causes a fall in the price of the aggregate warm glow characteristic $g$ via (8) and, in turn, an increase in total donations, $d$. This increase in $d$ is "lift". Second, the appeal changes the share:

$$
\frac{\partial \log \phi}{\partial \log \alpha_{s}}=-(1-\phi)(1-\sigma)
$$


The change in the share $\phi$ is what drives "shift". By "shift" we mean a donation pattern in which donations move in opposite directions: $s \uparrow r \downarrow$ or $s \downarrow r \uparrow$. If one of these patterns obtains, while at the same time there is an increase in total donations, then the fundraising intervention results in lift and shift. By contrast, if the observed donation pattern is $s \uparrow r \uparrow$ then there is lift but no shift. The final possibility is a limiting case (discussed below): shift with no lift - i.e. where $s \uparrow r \downarrow$ (or $s \downarrow r \uparrow$ ) offset each other completely.

Whether a fundraising appeal by one charity that lifts total donations also shifts donations to the fundraising charity from the others, depends on the size of the increase in total donations $d$, which depends on the magnitude of $\gamma$, relative to the change in the share $\phi$ which depends on $\sigma$. The following proposition states the exact conditions:

Proposition 1. In a static model with quasilinear utility and two warm glow characteristics in which the price elasticity of the aggregate of the two characteristics is $\gamma<-1$, the parameter space of the elasticity of substitution $\sigma \in[0,+\infty)$ is partitioned into three sets that align with the possible qualitative effects of a fundraising appeal by charity $S$ on donations to itself, $s$, and donations, $r$, to charity $R$.

$$
\begin{array}{lcc}
s \uparrow \mathrm{r} \downarrow & \text { iff } & |\gamma|<\sigma<\infty \\
s \uparrow \mathrm{r} \uparrow & \text { iff } & 1+(\gamma+1) \frac{\phi}{1-\phi}<\sigma<|\gamma| \\
s \downarrow \mathrm{r} \uparrow & \text { iff } & 0<\sigma<1+(\gamma+1) \frac{\phi}{1-\phi}
\end{array}
$$

Proof. Available on request.

Because $\gamma<-1$, we have $1+(\gamma+1) \frac{\phi}{1-\phi}<1$. Therefore the "middle set" (15) of the three-set partition covers values of $\sigma$ that imply the warm-glow characteristics, $\omega_{s}$ and $\omega_{r}$, are complements as well as values of $\sigma$ that imply they are substitutes. The substantive take-away point from the proposition is that the lift/shift 
in observed donation response patterns, which the empirical literature has focused on and that charitable organizations obviously care about, does not line up one-to-one with the elasticity of substitution in preferences defined over warm glow characteristics. Furthermore, while it would seem to be intuitive to conclude from a $s$ $\uparrow r \uparrow$ pattern that warm glow from $\omega_{s}$ and $\omega_{r}$ are complements in preferences, the proposition indicates such a pattern is not sufficient evidence upon which to base that conclusion. The reason is that a lift in total donations (expenditures) can obscure a preference-substitution relationship in warm glow. Sufficient evidence to conclude that there is substitution between the two sources of warm glow in preferences requires a shift pattern, specifically $s \uparrow r \downarrow$. In this case, the charity that launches the fundraising intervention gets more donations partly at the expense of the other charity and substitution between warm-glow characteristics is strong enough to make itself visible in the observed donation response pattern.

Sufficient evidence to conclude complementarity in warm-glow preferences is a shift in the opposite direction: $s \downarrow r \uparrow$. This outcome would imply that a charity's fundraising appeal lowers its own donations while serving to increase donations to other charities. That such an outcome is so unlikely to occur implies that using qualitative donation patterns to identify warm glow complementarity would be difficult if not, practically speaking, impossible.

If there is zero lift in donations (in the limit, as $\eta \rightarrow 0, \gamma \rightarrow-1$ ) the three-set partition collapses to a two-set partition - the middle set disappears - and the donation pattern will necessarily be either $s \uparrow r \downarrow$ if $\sigma>1$, or $s \downarrow r \uparrow$ if $\sigma<1$. Only in this special case does substitution/complementarity in donations reveal one-to-one whether the underlying warm glows are substitutes or complements.

Up to this point the model has been static, and the focus has been on lift and shift within the charity-space dimension. Our empirical results point to the need to include a time dimension. We therefore consider a two-period model in which the warm glow characteristic $g$ from (7) is indexed by $t=1$ and $t=2$. The characteristics $\omega_{s}$ and $\omega_{r}$ are also time-indexed.

Define a two-period aggregate warm glow characteristic:

$$
\tilde{\mathrm{g}}=\left(1 / 2 \mathrm{~g}_{1} \delta+1 / 2 \mathrm{~g}_{2} \delta\right)^{1 / \delta}
$$


where the intertemporal elasticity of substitution $\rho=1 /(1-\delta)$, and use $\tilde{\mathrm{g}}$ as a replacement for " $\mathrm{g}$ " in ( 3 '). Henceforth, a "tilde" indicates a two-period aggregate. Preferences are now a nested CES aggregation (Keller, 1976).

We assume unconstrained lending and borrowing at no interest between the time periods. This not only simplifies the interpretation of the results to come, but is reasonable because time differences between our $t=1$ and $t=2$ - the immediate aftermath of the appeal and the adjustment/settling - are measured in weeks. The effective price of the two-period aggregate warm glow characteristic $\tilde{g}$ is:

$$
p_{\tilde{\mathrm{g}}}=\left(p_{g 1}{ }^{1-\rho}+p_{g 2}{ }^{1-\rho}\right)^{1 /(1-\rho)}
$$

where $p_{g 1}$ and $p_{g 2}$ are time-indexed versions of (8). Optimal two-period total donations over the two periods are:

$$
\widetilde{d}^{*}=\widetilde{\mathrm{g}}^{*}\left(p_{g 1}{ }^{1-\rho}+p_{g 2}{ }^{1-\rho}\right)^{1 /(1-\rho)}
$$

where optimal $\tilde{\mathrm{g}}^{*}$ is as before (with $p_{\tilde{\mathrm{g}}}$ replacing $p_{g}$ ). These donations are split across time according to $d_{1}{ }^{*}=\widetilde{d}^{*} \tau$ and $d_{2}{ }^{*}=\widetilde{d}^{*}(1-\tau)$ where:

$$
\tau=\frac{p_{g 1}{ }^{1-\rho}}{p_{g 1}{ }^{1-\rho}+p_{g 2}{ }^{1-\rho}}
$$

is the share of two-period total donations $\widetilde{d}^{*}$ spent at $t=1 ; \tau\left(\alpha_{s 1}, \alpha_{r 1}, \alpha_{s 2}, \alpha_{r 2}, \sigma, \rho\right)$ is a function of the two effectiveness parameters (both indexed by time) and the two elasticities of substitution (in charity-space and intertemporal). Then within each period, donations are split between the two charities according to (10) and (11):

$$
\begin{array}{lcccc}
s_{1}{ }^{*} & = & \widetilde{d}^{*} & \tau & \phi \\
r_{1}{ }^{*} & = & \widetilde{d}^{*} & \tau & (1-\phi) \\
s_{2}{ }^{*} & = & \widetilde{d}^{*} & (1-\tau) & \phi \\
r_{2}{ }^{*} & = & \widetilde{d}^{*} & (1-\tau) & (1-\phi) .
\end{array}
$$


In (21)-(24), lift is an increase in $\widetilde{d}^{*}$ - total two-period expenditures on twoperiod aggregate warm glow $\tilde{g}^{*}$. Lift may or may not be accompanied by shift, which can now occur in two dimensions: $\tau$ drives time-shifting from $d_{2}{ }^{*}$ (the donation total at $t=2$ ) to $d_{1}{ }^{*}$ (the donation total at $t=1$ ) and $\phi$ drives shift in the charity-space dimension, as it did in the static model. The observed decrease in $r_{2}{ }^{*}$ in response to the DEC appeal can occur if the lift in two-period total donations $\widetilde{d}^{*}$ is more than offset by a reduction in the share $(1-\tau)$ of those donations spent at $t=2$ plus a reduction in the share $(1-\phi)$ of the $t=2$ donations spent on charity $R$.

To make the combination of lift/charity-space shift/time-shift concrete we derive the comparative statics of (21)-(24) in response to a fundraising appeal by charity $S$ that remains effective over two time periods. Specifically, we model a fundraising appeal as a two-tuple $\left(\partial \log \alpha_{s 1}, \partial \log \alpha_{s 2}\right)=(\partial \log \lambda, \xi \partial \log \lambda)$, where $\partial \log$ $\lambda$ models the strength of the appeal at $t=1$ and $0<\xi<1$ models the exponential decay rate of the appeal's effectiveness at $t=2$. In this way, a fundraising appeal is modelled as a single exogenous intervention that plays out over two time periods. Continuing the example of $r_{2}{ }^{*}$ from the previous paragraph, the comparative statics are:

$\partial \log r_{2}^{*}$ $\overline{\partial \log \lambda}=-(\gamma+1) \phi[\tau+(1-\tau) \xi]+(1-\rho) \phi \tau(1-\xi)+(1-\sigma) \phi \xi$.

The comparative statics of $s_{1}{ }^{*}, r_{1}{ }^{*}$ and $s_{2}{ }^{*}$ yield similar kinds of expressions. In each expression, the right-hand sides are boundaries in the $(\sigma, \rho)$ parameter space. For each boundary, taking $(25)$ as an example, the $(\sigma, \rho)$ pairs to one side of the boundary map to $\partial \log r_{2}{ }^{*} / \partial \log \lambda>0$, and pairs on the other side of the boundary map to $\partial \log$ $r_{2}{ }^{*} / \partial \log \lambda<0$. In this way, the $(\sigma, \rho)$-preference parameters describing the underlying warm glow characteristics map to qualitative response patterns in the donations.

In general, the four boundaries are nonlinear expressions linking $\sigma$ and $\rho$ in an (implicit) functional relationship. The expressions are nonlinear because $\phi(\cdot)$ is a nonlinear function of $\sigma$ and $\tau(\cdot)$ is a nonlinear function of both $\sigma$ and $\rho$. However, under an assumption that in the baseline time periods the effectiveness with which donations produce warm glow is time-invariant, the four functional relationships can be solved in closed form, allowing $\rho$ to be written as an explicit function of $\sigma$. 
Moreover, two of the functions are straight lines. Figure 4 provides an example with $\gamma$ $=-1.25, \xi=.5$, and baseline effectiveness parameters $\alpha_{s}=.05$ and $\alpha_{r}=1$. These values of the baseline effectiveness parameters can produce $\phi \approx .06$, which is the share of baseline donations going to $D E C-13$ in the CAF data. ${ }^{7}$

Figure 4 shows how the four boundaries from the comparative statics partition the $(\sigma, \rho)$ parameter space into multiple sets, each set corresponding to a specific qualitative donation response pattern. The qualitative donation response pattern that maps to each set is represented by a $2 \times 2$ matrix of + and - signs that describes each period's donation response for each charity. For example, the donation pattern in response to the DEC appeal observed in section 3 is represented as the following $2 \times 2$ matrix:

$$
\begin{array}{ll}
\Delta s_{1} & \Delta s_{2} \\
\Delta r_{1} & \Delta r_{2}
\end{array}=\begin{array}{ll}
s_{1} \uparrow & s_{2} \uparrow \\
r_{1} \uparrow & r_{2} \downarrow
\end{array}=\begin{aligned}
& +\quad+ \\
& +\quad-
\end{aligned}
$$

The set of $(\sigma, \rho)$ pairs consistent with this pattern is indicated by the shaded area in the figure. Note that in this set, all the values of the elasticity of substitution are $\sigma>1$ : the two warm glow characteristics are substitutes. We state this formally as Proposition 2.

Proposition 2. In a dynamic two-period model with quasilinear utility and two warm glow characteristics in which the price elasticity of the two-period aggregate of the warm glow characteristics is $\gamma<-1$, the decay rate in the fundraising appeal's effectiveness is $\xi<1$ and the baseline effectiveness with which donations produce warm glow is time-invariant, the qualitative donation pattern we observed $\left(s_{1} \uparrow r_{1} \uparrow\right.$ and $\left.s_{2} \uparrow r_{2} \downarrow\right)$ implies the two warm glow characteristics are substitutes.

\footnotetext{
${ }^{7}$ The time-invariant baseline effectiveness assumption is that $\alpha_{s 1}=\alpha_{s 2}$ and $\alpha_{r 1}=\alpha_{r 2}$. There are two substantive implications. The first is that, absent the fundraising appeal, the shares of donations going to charities $S$ and $R$ are not changing over time. The second is that the share of two-period total donations spent at $t=1$ and at $t=2$ are equal, that is $\tau=(1-\tau)=1 / 2$. Both implications are reasonable assumptions when differences between time periods are measured in weeks, and, in any event, can be effectively secured in empirical work by using a flexible set of time dummies. To ease the discussion we wrote (21)-(25) with time-invariant $\phi$. The counterpart equations with time-varying $\phi$ are available on request.
} 
Corollary 1. The donation response pattern we observed also implies $\rho>1$ : the time period 1 and 2 warm glow aggregate characteristics $g_{1}$ and $g_{2}$ are intertemporal substitutes.

Corollary 2. In the case where the underlying warm glow characteristics are substitutes, but weak enough substitutes so that the increase in total donations obscures charity-space substitution in the immediate $t=1$ aftermath of an appeal $(\sigma<$ $|\gamma|$ so $s \uparrow r \uparrow$; see Proposition 1), for a dynamic analysis to resolve the identification problem, it is necessary for $\rho>|\gamma|$. However, if $\rho$ is too large, the identification problem re-emerges.

Proofs of Corollary 1 and 2. Available on request. Note that although the graph in Figure 4 is specific in its illustration of the claims of the proposition and corollaries, the proofs are general.

The most important substantive implication of Proposition 2 is that donation evidence from a single time period—such as $s_{1} \uparrow r_{1} \uparrow$ — can have weak power to detect underlying substitution/complementarity in warm glow characteristics, weak compared to evidence from multiple time periods. In our case, if we only had data from the aftermath period and observed $s_{1} \uparrow r_{1} \uparrow$, we would have been unable to adjudicate whether $\omega_{s}$ and $\omega_{r}$ were substitutes or complements. However, additionally observing $s_{2} \uparrow r_{2} \downarrow$ is sufficient evidence to conclude that $\omega_{s}$ and $\omega_{r}$ are substitutes.

Whereas the lift in total donations works to obscure substitution/ complementarity in warm glow preferences, the role of time-shifting in identification is a two-edged sword. Time-shifting from $t=2$ to $t=1$ works in the same direction as the increase in total donations to make identification of substitution/ complementarity even more difficult at $t=1$. However, as in the case of the DEC appeal, time-shifting can work to offset the effect of lift in the second period (i.e. $r_{2} \downarrow$ ) making successful identification of substitution/ complementarity somewhat more likely.

Observing donations over a long time period may be the only way, practically speaking, for empirical investigations to successfully use qualitative donation patterns to identify warm glow complements. Recall in the discussion of Proposition 1 we pointed out that warm glow complements could be identified from a $s \downarrow r \uparrow$ pattern, but that a fundraising appeal lowering own donations was a perverse outcome and unlikely to occur. However, with time-shifting it may be possible to observe $s_{1} \uparrow r_{1} \uparrow$ 
and $s_{2} \downarrow r_{2} \uparrow$, and the latter would be sufficient evidence to identify warm glow complements. Essentially, for warm glow complements whose complementarity is too weak to be identified at $t=1$, time-shifting may be strong enough to reveal it at $t=2$.

In summary, a two-period model suggests that the donation patterns presented in Section 3 can be explained using standard economic constructs: the elasticity of substitution between goods and the intertemporal elasticity of substitution. The model also provides a framework for identifying underlying preferences from observed donation responses. In the case of the DEC appeal, the pattern implies that the warm glow produced by donations to $D E C-13$ is a substitute for the warm glow produced by donations to all other charities. The donation pattern also implies that warm glow is intertemporally substitutable. The model can also account for some of the differences in shift patterns that were observed in some of the empirical analyses. For example, the shift to $D E C-13$ from health driven by the stronger $r_{2} \downarrow$ identifies the respective warm glows as substitutes, and (holding the intertemporal elasticity of substitution $\rho$ constant), necessarily stronger substitutes than the DEC-13/all-Other-charities warm glows. The absence of time-shifting in donations to Other charities following the telethons indicates that the respective warm glows are weaker substitutes, and perhaps complements: the $(\sigma, \rho)$ pairs consistent with the telethon pattern lie on the $\mathrm{d} r_{2}=0$ line to the north-west of the $\mathrm{d} r_{l}=0$ line in Figure 4 (indicating weaker substitutes compared to the two DEC-13/Other warm glows, again at any value of $\rho$ held constant). If the Table $4-0.185$ insignificant point estimate for donations to telethon charities at $t=2$ is taken at face value, then the telethon pattern is $t e l_{1} \uparrow r_{1} \uparrow$ and $t e l_{2} \downarrow$ $\mathrm{d} r_{2}=0$ - the $(\sigma, \rho)$ pairs consistent with this on the $\mathrm{d} r_{2}=0$ line to the north-west of the $\mathrm{d} s_{2}=0$ curve, indicating complements.

\section{Conclusions}

We have developed a dynamic model with two sources of warm glow in which a fundraising appeal increases the share of donations going to the fundraising charity, and consequently decreases the share going to the non-fundraising charity. Whether this translates into shift — a drop in the donated amounts received by the nonfundraising charity - depends on whether or not lift— the increase in total donations spread across both the fundraising charity and the non-fundraising charity-exceeds the decreased share received by the later. 
Evidence from two types of fundraising appeals indicates that the increase in total donations offsets the decreased share. In both disaster appeals and telethon appeals, non-fundraising charities do not see a drop in the donated amount they receive. Surprisingly however, in the immediate aftermath of the appeals, nonfundraising charities see an increase in their donations. In the case of the disaster appeals, the increase is entirely negated by a subsequent decrease in donations. For telethons there is no subsequent decrease, implying donations to the non-fundraising charities increase, although the increase is small and not statistically significant.

The importance of this evidence, relative to that provided by previous papers, is that it is derived from data rich in both the charity space $(80,000$ organizations) and the time dimension (over 1,800 days). The results are based on the behavioral responses of over 100,000 people. These people represent the top two deciles of the distribution of charitable giving. Although results based on the behavior of people in lower deciles is of interest and a direction for future research, the present results are informative about the behavior of the population who do the large majority of charitable giving.

The results are relevant for social welfare analyses of fundraising. The data we use, rich though they are, are not sufficient in and of themselves to carry out a complete social welfare analysis, but they yield evidence that complements previous welfare analyses (e.g., DellaVigna, List, and Malmendier, 2012; Andreoni, Rao, and Trachtman, 2017). Previous analyses have not been able to take into account the possibility that fundraising merely shifts donations from other charities (altering the mix of public goods) or from the future (merely altering the timing). The present evidence that fundraising does not lead to a fall in donations received by nonfundraising charities - and that time shifting is not a factor for the fundraising charities themselves, while for the non-fundraising charities any time shifting plays out within twenty weeks - suggests that had previous welfare analyses been able to account for shifting in charity space and time, the change in their conclusions, if any, would have been minor.

The comparative static results from the dynamic two-warm glow model are significant because they establish an identification framework that maps qualitative donation response patterns to underlying warm glow preference parameters. The results indicate that the donation response-to-preference parameter map is not one-toone. For example, and somewhat surprisingly, an increase in donations received by 
both the fundraising and non-fundraising charities does not imply that the respective warm glows are complements. That is because the lift in total donations can lead to an increase for both fundraising and non-fundraising charities even if the underlying warm glows are substitutes. If the underlying warm glows are strong enough substitutes, it is more likely that donation patterns would be successful in revealing that, more successful than the patterns would be in revealing underlying complementarity. The reason is that to identify underlying complementarity the qualitative donation pattern would have to detect a (counter-intuitive) drop in donations received by the charity doing the fundraising. However, we argue that observing donations responses over a longer timer period gives a complementary relationship more of a chance to be detected.

Detecting underlying substitution (between the two warm glows) using a qualitative donation pattern requires detecting a drop in donations received by the non-fundraising charity. While it is obvious that successfully detecting substitution may require observing donations in a suitably "wide" charity space, it is less obvious that detecting substitution between two warm glows can be facilitated by observing donations over a longer time period. The model explains how this can work: intertemporal substitution can in later time periods offset the lift in total donations that would otherwise obscure the underlying substitution.

This is not just a theoretical curiosity. In both types of appeals we investigated, donations received by the non-fundraising charities increased in the immediate aftermath of the appeal. Indeed, it is only because the data we used continued to observe donation responses throughout the adjustment and settling periods that we were able to detect the subsequent drop in donations received by the non-fundraising charities following the disaster appeals. From this result, and using the dynamic identification framework, we are able to draw two conclusions. First, the warm glow derived from giving to disaster relief is a substitute for the warm glow derived from giving to other charities in general, and to health charities in particular. Second, the warm glow derived from giving to charities is intertemporally substitutable. These two results extend our conceptual understanding of warm glow. To our knowledge these are the first results that warm glow is substitutable between charities. And although there has been some previous lab evidence consistent with warm glow being intertemporally substitutable (Tonin and Vlassopoulis, 2014), we 
are not aware of previous evidence of intertemporal substitutability based on realworld donation behavior.

Finally, the results have implications for future research. First, lift/shift studies have a better chance for success in using qualitative donation responses to detect underlying substitution/complementarity relationships if the study design is high frequency, long duration in the time dimension. Second, there is a limit to what can be learned about underlying substitution/complementarity relationships using qualitative donation responses, a limit that is clarified by the dynamic identification framework. The framework also makes clear what is necessary to learn more: quantification of the change, caused by fundraising, in the effectiveness with which donations produce warm glow. If that change can be quantified, then the degree of substitution/ complementarity and the degree of intertemporal substitutability can be point identified. Therefore, quantifying and measuring this change is an important area for future research.

In summary, using data rich in both the space of charities and dimension of time we find evidence that fundraising appeals increase donations to the charities doing the fundraising, but that the increase does not come at the expense of a general decrease in donations to the non-fundraising charities. The fundraising appeals we studied produced more lift in total donations than a decrease in the share of donation received by the non-fundraising charities. That said, the dynamic identification framework we developed indicates that the time-shifting observed for the nonfundraising charities following disaster appeals is evidence that the respective warm glows derived from donating to disaster relief and donating to the non-fundraising charities are, in fact, substitutes. It may be that an intuitive sense of this warm glow substitution is what has led many observers of the charity sector to argue that successful fundraising must necessarily come at the expense of decreased donations to other charities. What this argument fails to account for is lift. 


\section{References}

Alpizar, Francisco, Fredrik Carlsson, and Olof Johansson-Stenman. 2008. "Anonymity, Reciprocity, and Conformity: Evidence from Voluntary Contributions to a National Park in Costa Rica.” Journal of Public Economics, 92(5): 1047-1060.

Andreoni, James, and A. Abigail Payne. 2013. "Charitable Giving," In Handbook of Public Economics, Vol. 5, ed. Alan Auerbach, Raj Chetty, Martin Feldstein, and Emmanuel Saez, 1-50. Amsterdam: North Holland.

Andreoni, James, Justin M. Rao, and Hannah Trachtman. 2017. "Avoiding the Ask: A Field Experiment on Altruism, Empathy, and Charitable Giving." Journal of Political Economy, 125(3): 625-653.

Bekkers, René. 2015. "When and Why Matches Are More Effective Subsidies Than Rebates." Research in Experimental Economics, Volume 18: Replication in Economic Experiments. Edited by Deck, C. Fatas, E., and Rosenblat, T. Emerald Group Publishing.

Bentzen, Jeanet Sinding. 2015. "Acts of God? Religiosity and Natural Disasters Across Subnational World Districts.” Discussion Paper 15-06, Department of Economics, University of Copenhagen.

Bernstein, Elizabeth. 2005. "Katrina Giving Cuts Donations to Other Groups." The Wall Street Journal. http://www.wsj.com/articles/SB112717005910945455

Brown, Sarah, Mark N. Harris, and Karl Taylor. 2012. "Modelling Charitable Donations to An Unexpected Natural Disaster: Evidence from the U.S. Panel Study of Income Dynamics." Journal of Economic Behavior and Organization, 84(1): 97-110.

Cairnes, Jason, and Robert Slonim. 2011. "Substitution Effects Across Charitable Donations." Economics Letters, 111(2): 173-175.

Carpenter, Jeffrey, and Peter Hans Matthews. 2017. "Using Raffles to Fund Public Goods: Lessons from a Field Experiment." Journal of Public Economics, 150: 30-38.

Cornes, Richard, and Todd Sandler. 1984. "Easy Riders, Joint Production, and Public Goods." The Economic Journal, 94(375): 580-598.

De Alessi, Louis. 1975. "Toward an Analysis of Postdisaster Co-operation.” The American Economic Review. 65(1): 127-138.

DellaVigna, Stefano, John A. List, and Ulrike Malmendier. 2012. "Testing for Altruism and Social Pressure in Charitable Giving." Quarterly Journal of Economics, 127(1): $1-56$.

Deryugina, Tatyana, and Benjamin Marx. 2015. "Do Causes Crowd Each Other Out? Evidence from Tornado Strikes." Unpublished.

Diewert, Erwin W. (2014). "Microeconomic Theory: A Dual Approach.” Unpublished lecture notes (p. 19), Department of Economics, University of British Columbia, Vancouver.

Donkers, Bas, Merel van Diepen, and Philip Hans Franses. 2017. "Do Charities Get More When They Ask More Often? Evidence from a Unique Field Experiment." Journal of Behavioral and Experimental Economics, 66: 58-65. 
Eckel, Catherine, and Philip Grossman. 2008. "Subsidizing Charitable Contributions: A Natural Field Experiment Comparing Matching and Rebate Subsidies." Experimental Economics, 11(3): 234-252.

Eisensee, Thomas, and David Strömberg. 2007. "News Droughts, News Floods, and U. S. Disaster Relief." Quarterly Journal of Economics, 122(2): 693-728.

Ek, Claes. 2017. "Some Causes are More Equal than Others? The Effect of Similarity on Substitution in Charitable Giving." Journal of Economic Behavior and Organization, 136: 45-62.

Falk, Armin. 2007. "Gift Exchange in the Field.” Econometrica, 75(5): 1501-1511.

Fidrmuc, Jan, Sugata Gosh, and Weonho Yang. 2015. "Natural Disasters, Government Spending, and the Fiscal Multiplier." CESifo Working Paper, No. 5665.

Filiz-Ozbay, Emel, and Neslihan Uler. 2017. "Demand for Giving to Multiple Charities: An Experimental Study." Unpublished.

Harbaugh, William. 1998. "The Prestige Motive for Making Charitable Transfers." American Economic Review, 88(2): 277-282.

Harwell, Haley, Daniel Meneses, Chris Moceri, Marc Rauckhorst, Adam Zindler, and Catherine Eckel. 2015. "Did the Ice Bucket Challenge Drain the Philanthropic Reservoir?" Working Paper, Economic Research Laboratory, Texas AandM University.

Huck, Steffen and Imran Rasul. 2010. "Transactions Costs in Charitable Giving: Evidence from Two Field Experiments." The B.E. Journal of Economic Analysis and Policy, 10(1): Article 31: 1-32.

Huck, Steffen, and Imran Rasul. 2011. "Matched Fundraising: Evidence from a Natural Field Experiment." Journal of Public Economics, 95: 351-62.

Karlan, Dean and John A. List. 2007. "Does Price Matter in Charitable Giving? Evidence from a Large-Scale Natural Field Experiment." American Economic Review, 97(5): 1774-93.

Keller, Wouter J. 1976. "A Nested CES-type Utility Function and its Demand and Priceindex Functions." European Economic Review, 7: 175-186.

Klar, Samara, and Spencer Piston. 2015. "The Influence of Competing Organisational Appeals on Individual Donations." Journal of Public Policy, 35(2): 171-191.

Krieg, Justin, and Anya Samek. 2017. "When Charities Compete: A Laboratory Experiment with Simultaneous Public Goods." Journal of Behavioral and Experimental Economics, 66: 40-57.

Landry, Craig E., Andreas Lange, John A. List, Michael K. Price, and Nicholas G. Rupp. 2006. "Toward an Understanding of the Economics of Charity: Evidence from a Field Experiment." Quarterly Journal of Economics, 121(2): 747-82. . 2010. "Is a Donor in Hand Better than Two in the Bush? Evidence from a Natural Field Experiment." American Economic Review, 100(2): 958-83. 
Lange, Andreas, John A. List, and Michael K. Price. 2007. "Using Lotteries to Finance Public Goods: Theory and Experimental Evidence." International Economic Review, 48(3): 901-27.

Lange, Andreas, and Andrew Stocking. 2012. "The Complementarities of Competition in Charitable Fundraising.” Working Paper. Congressional Budget Office, Washington, DC.

List, John A. 2011. "The Market for Charitable Giving." Journal of Economic Perspectives, 25(2): 157-80.

MacAskill, William. 2014.”The Cold, Hard Truth About the Ice Bucket Challenge." Quartz. https://qz.com/249649/the-cold-hard-truth-about-the-ice-bucket-challenge/

Meer, Jonathan, and Oren Rigbi. 2013. "The Effects of Transactions Costs and Social Distance: Evidence from a Field Experiment." The B.E. Journal of Economic Analysis and Policy, 13(1): 271-296.

Meer, Jonathan. 2017. "Does Fundraising Create New Giving?” Journal of Public Economics, 145(C): 82-93.

Meier, Stephan. 2007. "Do Subsidies Increase Charitable Giving in the Long Run? Matching Donations in a Field Experiment." Journal of the European Economic Association, 5(6): 1203-1222.

Morgan, John. 2000. "Financing Public Goods by Means of Lotteries." Review of Economic Studies, 67(4): 761-84.

Morgan, John, and Martin Sefton. 2000. "Funding Public Goods with Lotteries: Experimental Evidence." Review of Economic Studies, 67(4): 785-810.

Rao, Lin-Lin, Ru Han, Xiao-Peng Ren, Xin-Wen Bai, Rui Zheng, Huan Liu, Zuo-Jun Wang, Jin-Zhen Li, Kan Zhang, and Shu Li. 2011. "Disadvantage and Prosocial Behavior: The Effects of the Wenchuan earthquake." Evolution and Human Behavior, 32(1): 63-69.

Reinstein, David A. 2011. "Does One Charitable Contribution Come at the Expense of Another?" The B.E. Journal of Economic Analysis and Policy, Vol. 11(1): Article 40.

Riley, Tess. 2014. "ALS Ice Bucket Challenge is not a Catalyst for Long-term Behaviour Change." The Guardian Newspaper. https://www.theguardian.com/sustainablebusiness/2014/sep/05/als-ice-bucket-challenge-long-term-behaviour-change

Rose-Ackerman, Susan. 1982. "Charitable Giving and 'Excessive' Fundraising." Quarterly Journal of Economics, 97 (2): 193-212.

Shang, Jen, and Rachel Croson. 2009. "A Field Experiment in Charitable Contribution: The Impact of Social Information on the Voluntary Provision of Public Goods." The Economic Journal, 119: 1422-1439.

Salamon, Lester M., and Helmut K. Anheier. 1996. The Emerging Nonprofit Sector: An Overview. Manchester: Manchester University Press.

Solnit, Rebecca. 2009. A Paradise Built in Hell: The Extraordinary Communities that Arise in Disaster. New York: Penguin Books. 
Tonin, Mirco, and Michael Vlassopoulos. 2014. "An Experimental Investigation of Intrinsic Motivations for Giving." Theory and Decision, 76(1): 47-67.

van Diepen, Merel, Bas Donkers, and Philip Hans Franses. 2009. "Dynamic and Competitive Effects of Direct Mailings: A Charitable Giving Application." Journal of Marketing Research, 46(1): 120-133. 


\section{Figure 1: Estimated response to DEC appeals, by week}
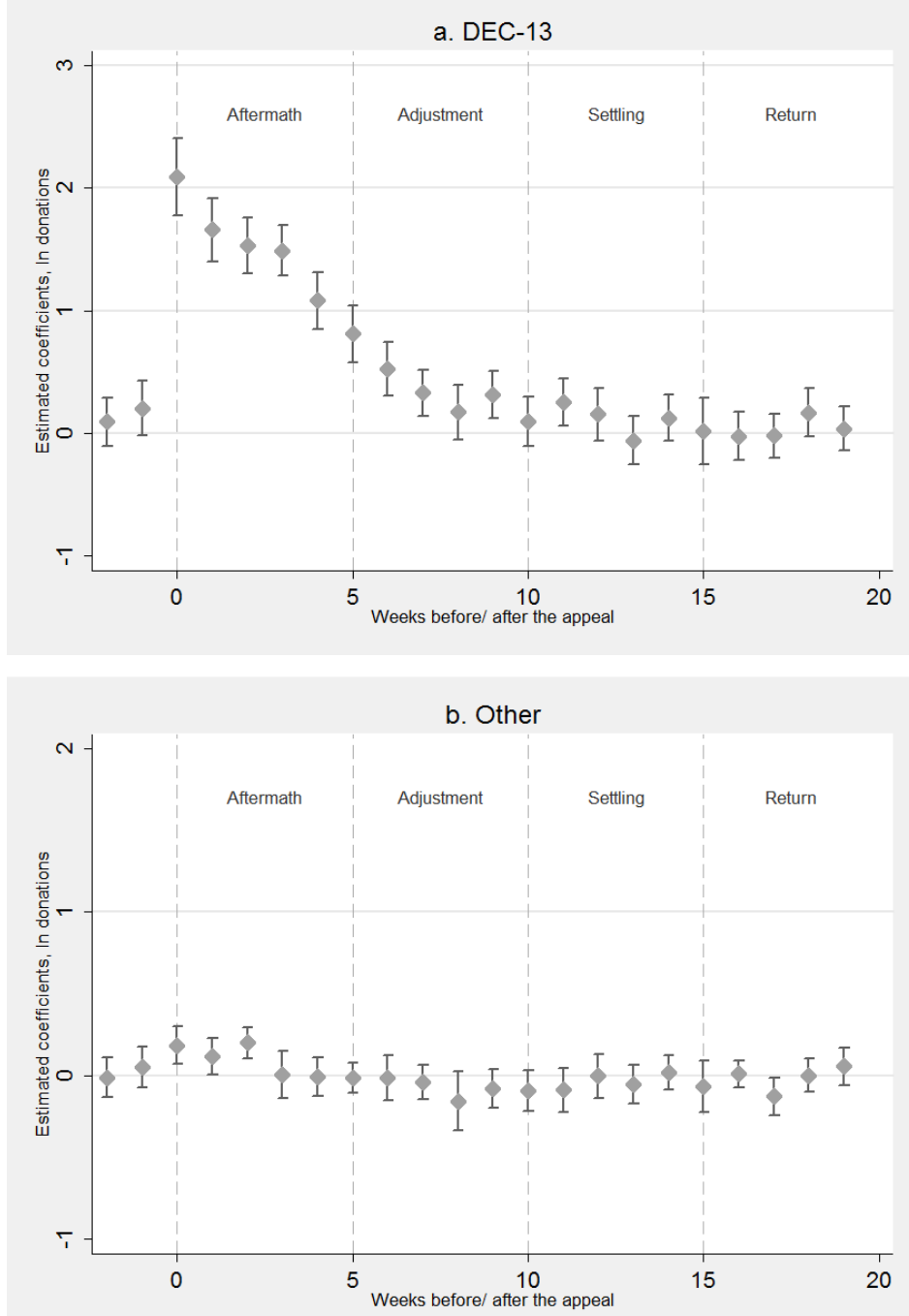

Notes to figure: $\underline{D E C-13}$ is donations to the Disasters Emergency Committee (DEC) and its thirteen member charities (Action Aid, Age International, British Red Cross, CAFOD, Care International, Christian Aid, Concern Worldwide, Islamic Relief, Oxfam, Plan UK, Save the Children, Tearfund and World Vision). Other is donations to all other charities. The coefficients capture the difference in average (In) donations, relative to baseline (non-appeal) periods. Panel b's vertical scale is smaller than Panel a's. 
Figure 2: Residual donations during response and baseline periods

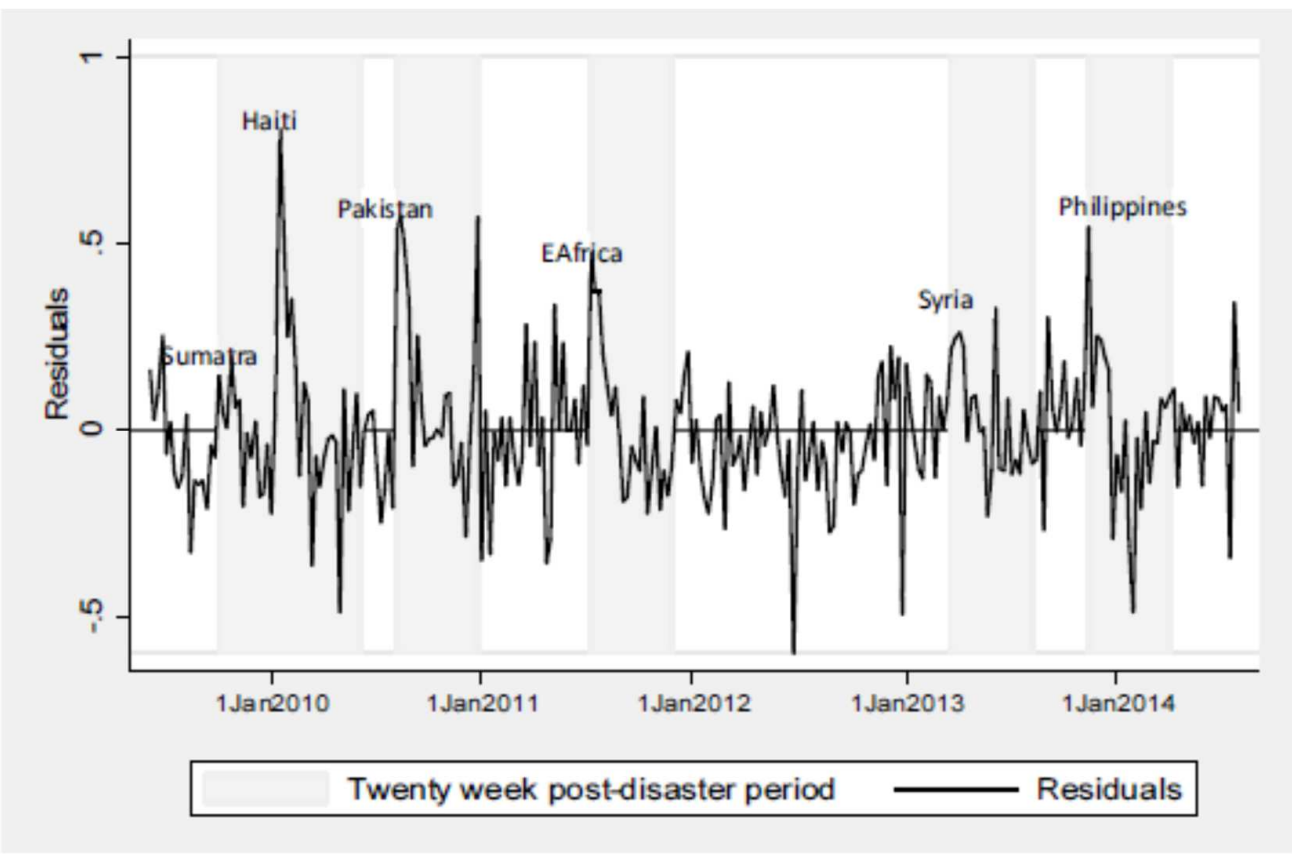

Note to figure: Weekly-averaged residuals from OLS regression including systematic time controls, excluding weekly indicators. The grey bands indicate the twenty-week post-appeal period. The second disaster (Haiti) occurred within 20 weeks of the first disaster (Sumatra) - this explains why the first shaded bar is wider, and why the Haiti spike occurs in the middle of the bar. 
Figure 3: Estimated response to telethon appeals, by week

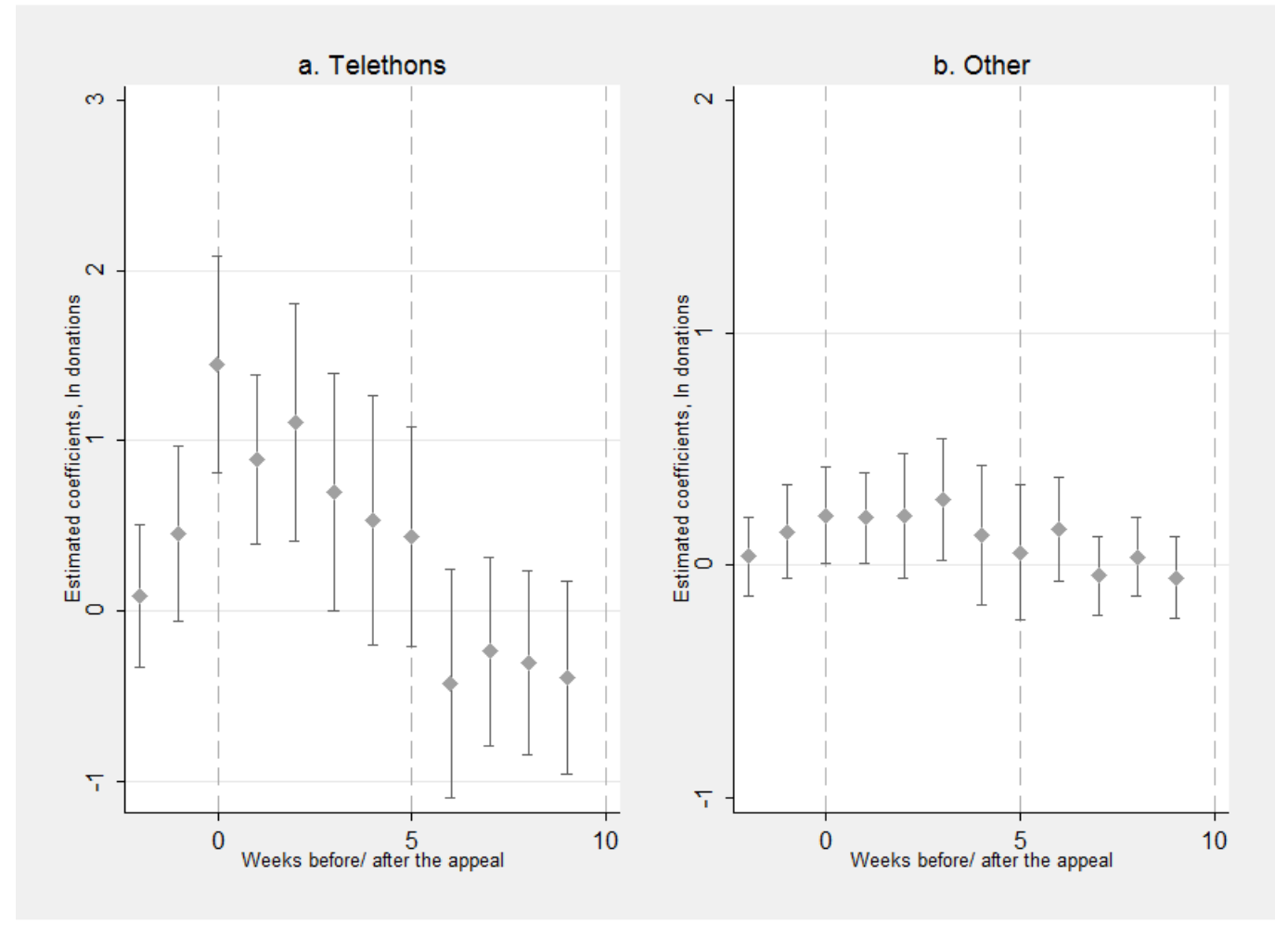

Notes to figure: Telethons are comprised of donations to a set of charities that allocate funds, including BBC Children in Need and Comic Relief/Sports Relief. Other is donations to all other charities. The coefficients capture the difference in average (In) donations, relative to baseline (non-appeal) periods. The six twenty-week post-DEC appeal periods are excluded from the analysis. Panel b's vertical scale is smaller than Panel a's. 


\section{Figure 4. Warm glow preference parameters mapped to donation response patterns}

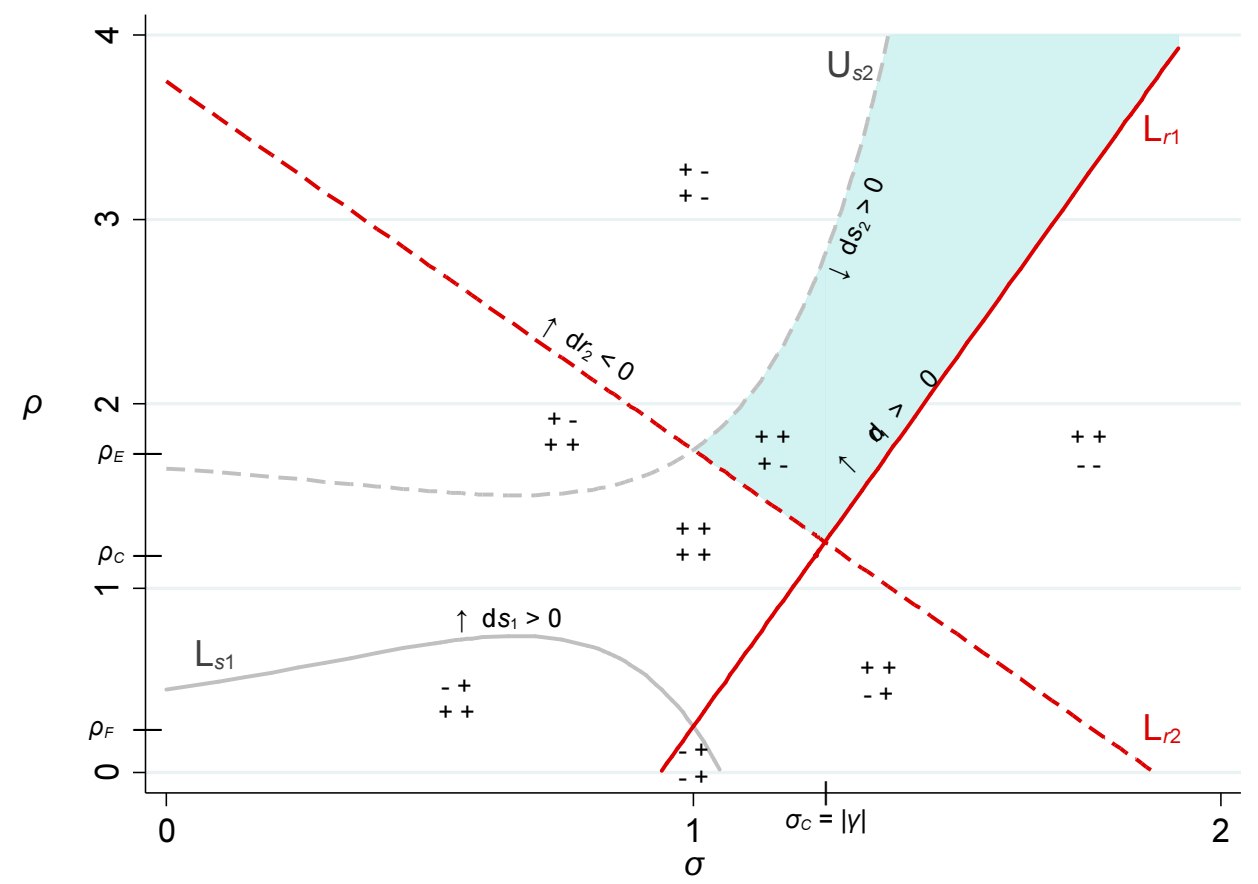

Note to figure: Preference parameters are on the $x$-and $y$-axes. The $x$-axis is the elasticity of substitution between the two warm glows produced by donations to two different charities. The $y$-axis is the intertemporal substitution between aggregate warm glow in time periods $t=1$ and $t=2$; see equations (7) and (17). Donation response patterns are indicated by the + and - signs in the graph. For example, “+ +" over “+ - " in the shaded area indicates $s_{1} \uparrow r_{1} \uparrow$ and $s_{2} \uparrow r_{2} \downarrow$, the observed pattern following the DEC appeals. The shaded area are the $\sigma, \rho$ pairs consistent with that response pattern. The two curves (for $s_{1}$ and $s_{2}$ ) and two straight lines (for $r_{1}$ and $r_{2}$ ) are boundaries such that the direction of the donation response is different on either side of the boundary. For example, " $\uparrow \mathrm{d} r_{I}$ $>0$ " on the solid red line indicates that for $\sigma, \rho$ pairs above $(\uparrow)$ the line, the appeal by charity S causes donations to charity $R$ to increase at $t=1\left(\mathrm{~d} r_{1}>0\right)$; for $\sigma, \rho$ pairs below the line the $S$ appeal would cause $r_{l}$ to decrease. The figure is drawn with $\gamma=-1.25$ (price elasticity of two-period aggregate warm glow), $\xi=.5$ (decay rate of the appeal's effectiveness), and $\alpha_{s}=.05, \alpha_{r}=1$ (baseline effectiveness parameters). 


\section{Table 1: DEC appeals}

\begin{tabular}{lllc}
\hline Date of appeal & Location & Cause & $\begin{array}{c}\text { Total donations } \\
\text { reported by DEC }\end{array}$ \\
\hline $10 / 04 / 2009$ & Sumatra & Earthquakes and Typhoons & $£ 9.3 \mathrm{~m}$ \\
$01 / 14 / 2010$ & Haiti & Earthquake & $£ 107 \mathrm{~m}$ \\
$08 / 03 / 2010$ & Pakistan & Floods & $£ 71 \mathrm{~m}$ \\
$07 / 06 / 2011$ & East Africa & Famine & $£ 79 \mathrm{~m}$ \\
$03 / 20 / 2013$ & Syria & Civil War & $£ 27 \mathrm{~m}$ \\
$11 / 11 / 2013$ & Philippines & Typhoon & $£ 95 \mathrm{~m}$ \\
\hline
\end{tabular}

Notes to table: All information from Disasters Emergency Committee (http://www.dec.org.uk).

Sumatra: A series of devastating natural disasters (typhoons and quakes) hit Indonesia, the Philippines and Vietnam within a number of days. DEC reported that over five million were affected.

Haiti: An earthquake devastated the capital, Port au Prince, and the surrounding area. DEC reported that 1.5 million people lost their homes, 300,000 were injured and 220,000 died.

Pakistan: Floods swept the country following the worst monsoon rains in the country's history. DEC reported that more than 18 million people were affected.

East Africa: DEC reported that more than 13 million people in Ethiopia, Kenya, Somalia, and the Republic of South Sudan were left in need of food, water and emergency healthcare because of one of the worst droughts in 25 years.

Syria: DEC reported that two years of war left more than nine million people in need of aid. About 1.2 million houses had been damaged. An estimated 6.5 million people were displaced inside Syria, and 2.5 million people had fled to the neighbouring countries of Jordan, Lebanon, Turkey and Iraq. Philippines: Typhoon Haiyan tore a path of destruction through central Philippines and DEC reported that over 14 million people were affected.

To put the size of the responses in context, estimated total individual giving in the UK is around $£ 7.0$ billion a year, the leading fundraising charity (Cancer Research UK) raises $£ 450$ million per year, the two national telethons that we study raise £50-100 million. 
Table 2: Main results - estimated responses to DEC appeals

Dependent variable $=\operatorname{Ln}($ donations $)$

\begin{tabular}{|c|c|c|c|c|}
\hline Aftermath & Adjustment & Settling & Return & $\begin{array}{l}\text { Entire } \\
\text { response } \\
\text { period }\end{array}$ \\
\hline eks $0-4$ & Weeks 5-9 & Weeks 10-14 & Weeks 15-19 & Weeks 0-19 \\
\hline
\end{tabular}

Panel a. Donations to $D E C-13$ and $O$ ther

$\begin{array}{lccccc}\text { DEC-13 } & 1.571 & 0.429 & 0.112 & 0.035 & 0.537 \\ (£ 10,331) & (0.060) & (0.052) & (0.050) & (0.051) & (0.032)\end{array}$

$\begin{array}{llllll}\text { Other charities } & 0.100 & -0.062 & -0.045 & -0.026 & -0.008\end{array}$

$\begin{array}{llllll}(£ 157,836) & (0.028) & (0.032) & (0.030) & (0.028) & (0.017)\end{array}$

Panel b. Total donations (DEC-13+Other)

$\begin{array}{lccccc}\text { Total donations } & 0.332 & -0.016 & -0.028 & -0.015 & 0.068 \\ (\mathfrak{A} 168,167) & (0.033) & (0.032) & (0.031) & (0.029) & (0.018)\end{array}$

$(£ 168,167)$

$(0.033)$

$(0.032)$

$(0.031)$

$(0.029)$

$(0.018)$

Notes. The table reports the average response (the mean of the estimated weekly coefficients) during different phases of the response period, compared to baseline. All regressions (estimated using OLS) include controls for systematic time effects (indicators for day of week, day of month, month, public holidays and major telethons and a linear trend). The amounts given are average daily donations (in pounds) during the baseline periods; these indicate the relative amounts given to different causes. 
Table 3: Further analysis of the DEC appeals

Dependent variable $=\operatorname{Ln}($ donations $)$

\begin{tabular}{|c|c|c|c|c|c|}
\hline & Aftermath & Adjustment & Weeks 10-14 & Weeks 15-19 & $\begin{array}{c}\text { Entire } \\
\text { response } \\
\text { period } \\
\text { Weeks 0-19 } \\
\end{array}$ \\
\hline \multicolumn{6}{|c|}{ Panel a. Sub-categories of Other charities } \\
\hline $\begin{array}{l}\text { Other international } \\
(£ 16,898) \\
\text { Non-international } \\
(£ 119,033)\end{array}$ & $\begin{array}{c}0.295 \\
(0.039) \\
0.068 \\
(0.028)\end{array}$ & $\begin{array}{l}-0.048 \\
(0.043) \\
-0.067 \\
(0.032)\end{array}$ & $\begin{array}{l}-0.045 \\
(0.040) \\
-0.047 \\
(0.031)\end{array}$ & $\begin{array}{l}-0.033 \\
(0.037) \\
-0.024 \\
(0.018)\end{array}$ & $\begin{array}{c}0.042 \\
(0.023) \\
-0.018 \\
(0.018)\end{array}$ \\
\hline $\begin{array}{l}\text { Ten "non-disaster" } \\
\text { charities }(£ 15,260)\end{array}$ & $\begin{array}{c}0.100 \\
(0.048)\end{array}$ & $\begin{array}{l}-0.110 \\
(0.054)\end{array}$ & $\begin{array}{l}-0.046 \\
(0.050)\end{array}$ & $\begin{array}{l}-0.027 \\
(0.048)\end{array}$ & $\begin{array}{l}-0.020 \\
(0.029)\end{array}$ \\
\hline \multicolumn{6}{|c|}{ Panel b. Sub-categories of Non-international charities } \\
\hline $\begin{array}{l}\text { Religious } \\
(£ 36,154) \\
\text { Health } \\
(£ 27,587) \\
\text { Social Services } \\
(£ 14,660) \\
\text { Education } \\
(£ 12,931) \\
\text { Environment } \\
(£ 6,891) \\
\text { Other } \\
(£ 42,711) \\
\end{array}$ & $\begin{array}{c}0.043 \\
(0.037) \\
0.096 \\
(0.038) \\
0.104 \\
(0.040) \\
0.051 \\
(0.046) \\
0.038 \\
(0.059) \\
0.071 \\
(0.037) \\
\end{array}$ & $\begin{array}{l}-0.026 \\
(0.039) \\
-0.161 \\
(0.046) \\
-0.055 \\
(0.045) \\
-0.059 \\
(0.048) \\
-0.039 \\
(0.054) \\
-0.080 \\
(0.043)\end{array}$ & $\begin{array}{l}-0.066 \\
(0.038) \\
-0.089 \\
(0.042) \\
-0.050 \\
(0.046) \\
-0.025 \\
(0.051) \\
0.004 \\
(0.050) \\
-0.026 \\
(0.038)\end{array}$ & $\begin{array}{c}-0.036 \\
(0.036) \\
-0.065 \\
(0.038) \\
0.005 \\
(0.037) \\
-0.012 \\
(0.051) \\
0.044 \\
(0.049) \\
-0.012 \\
(0.041) \\
\end{array}$ & $\begin{array}{c}-0.021 \\
(0.023) \\
-0.055 \\
(0.024) \\
0.001 \\
(0.037) \\
-0.011 \\
(0.028) \\
0.012 \\
(0.030) \\
-0.012 \\
(0.023)\end{array}$ \\
\hline \multicolumn{6}{|c|}{ Panel c. Donations to Other charities, by donor type } \\
\hline $\begin{array}{l}\text { Other, Disaster } \\
\text { donors only } \\
\text { Other, Non-dis } \\
\text { donors only }\end{array}$ & $\begin{array}{c}0.154 \\
(0.034) \\
0.009 \\
(0.033)\end{array}$ & $\begin{array}{l}-0.061 \\
(0.035) \\
-0.036 \\
(0.039)\end{array}$ & $\begin{array}{l}-0.038 \\
(0.037) \\
-0.037 \\
(0.035)\end{array}$ & $\begin{array}{c}0.034 \\
(0.032) \\
-0.071 \\
(0.033)\end{array}$ & $\begin{array}{c}0.022 \\
(0.020) \\
-0.034 \\
(0.020)\end{array}$ \\
\hline \multicolumn{6}{|c|}{$\begin{array}{l}\text { Notes. The table reports the average response (the mean of the estimated weekly coefficients) during } \\
\text { different phases of the response period, compared to baseline. All regressions (estimated using OLS) } \\
\text { include controls for systematic time effects (indicators for day of week, day of month, month, public } \\
\text { holidays and major telethons and a linear trend). Categories of charities based on their purpose follow } \\
\text { the International Classification of Non-Profit Organisations (Salamon and Anheier, 1996). } \\
\text { Non-disaster charities comprise the largest charities that we are confident are not involved in disaster } \\
\text { relief. Cancer Research UK, Salvation Army, National Society for the Prevention of Cruelty to } \\
\text { Children, Macmillan Cancer Relief, Shelter, Age UK, Royal Commonwealth Society for the Blind, } \\
\text { Royal National Lifeboats Institution, Marie Curie, British Heart Foundation, Alzheimers, Samaritans, } \\
\text { Barnados, World Wildlife Fund. } \\
\text { Disaster donors are those who give to DEC-13 during any of the response periods. } \\
\text { The amounts reported are the average daily donations (in pounds) during the baseline periods; these } \\
\text { indicate the relative amounts given to different causes. }\end{array}$} \\
\hline
\end{tabular}


Table 4: Estimated responses to telethon appeals

Dependent variable $=\operatorname{Ln}($ donations $)$

\begin{tabular}{lccc}
\hline & Aftermath & Adjustment & $\begin{array}{c}\text { Entire response } \\
\text { period } \\
\text { Weeks 0-9 }\end{array}$ \\
\hline Telethons & 0.935 & Weeks 5-9 & 0.375 \\
Other charities & $(0.270)$ & -0.185 & $(0.213)$ \\
& 0.210 & $(0.234)$ & 0.122 \\
Total & $(0.101)$ & 0.034 & $(0.076)$ \\
& 0.256 & $(0.076)$ & 0.144 \\
& $(0.100)$ & 0.032 & $(0.075)$ \\
\hline
\end{tabular}

Notes. Telethons are comprised of donations to a set of charities that allocate funds, including BBC Children in Need and Comic Relief/Sports Relief. Other is donations to all other charities. The table reports the average response (the mean of the estimated weekly coefficients) during different phases of the response period, compared to baseline. All regressions (estimated using OLS) include controls for systematic time effects (indicators for day of week, day of month, month, public holidays and a linear trend). The six twenty-week post-DEC appeal periods are excluded from the analysis. 


\section{Supplementary information, not intended for publication}

\section{Appendix A:}

\section{Further information on CAF account data and comparison with $U K$ Giving}

CAF accounts work like dedicated checking accounts for making donations to charities. Anyone could use a regular bank account to make the same donations, but there are a least two reasons why someone might want to set up a CAF account - first, it facilitates tax-effective giving and second, it may act as a commitment device to encourage giving. We discuss each of these in turn.

The UK system of tax relief for charitable donations, known as Gift Aid, differs to the US system. Unlike the US income tax rebate through itemized charitable deductions, the UK government operates an effective match system, allowing the charity to claim tax relief on donations at the basic rate of tax, currently 20 per cent. However, for the charity to claim the relief, the donor must fill out a Gift Aid declaration for each donation made. Since CAF is itself a charity, the donor has to do this only once when the account is opened, and not each time thereafter when a donation is made from the account to a charity. There is also a second element to Gift Aid: Taxpayers whose marginal tax rate is higher than the basic 20 per cent can reclaim an additional rebate equal to the difference between their marginal rate of tax and the basic 20 percent; using a CAF account provides a record of donations for this reclaiming.

The second reason for having a CAF account is that it can help individuals manage their giving and commit them to making a certain level of donations to charity. Money paid in cannot be withdrawn (any unspent funds are allocated by CAF), committing the account holder to donate the funds to charity.

\section{Comparison with UK Giving}

From the above we can infer from the fact that people set up a CAF account that they have a high level of interest in giving, and also in giving tax-effectively. Other than that, we have very limited demographic information about CAF account-holders upon which we can base comparisons with other people in the UK. Therefore we compare donations made by CAF account holders with donations made by donors in a random sample from the UK population. Our benchmark is the NCVO/CAF survey of 
individual giving, UK Giving, which collects information about charitable donations from adults aged 16 and over in the United Kingdom.

In 2010 UK Giving ran three times during the year (in June, October and February) as a module in the Omnibus survey conducted by the Office for National Statistics (ONS). This is a multipurpose, random-probability survey carried out face-to-face in people's homes, using Computer-Assisted Personal Interviewing (CAPI). Those interviewed are asked whether they have given to charity in the last four weeks by any of nine methods shown on a card. ${ }^{8}$ For each of the reported methods, they are asked which of fifteen types of causes they have donated to. Then for each cause donated to by each method, they are asked how much they gave. This information is aggregated into a figure for total donations.

We compare monthly donations from UK Giving 2010 to donations per accountholder, per month by CAF account holders in 2010. In short, the comparison indicates that the CAF data capture both a small number of donors who give very large amounts but are not picked up at all UK Giving, and a large number of donors who represent the top two deciles in UK Giving. The details follow.

Table A1 shows that CAF account holders give much more than the donors in $U K$ Giving - mean monthly donations in column II are $£ 278.94$ among CAF account holders compared to $£ 33.42$ in UK Giving (column I). Some of this difference is attributable to a small number of donors in the CAF sample who give very large donations, who are rarely picked up in random population surveys. Among CAF account holders, the largest monthly donation was $£ 1.5$ million, compared to $£ 1,330$ in UK Giving. In this respect, looking at CAF account-holders allows us to capture the behaviour of an important group of donors, who make very large donations, but who are typically missing in general household surveys. Indeed, in the CAF data, donations greater than $£ 1,330$ per month account for 43 per cent of all donations made by account holders.

\footnotetext{
${ }^{8}$ Buying goods (eg charity shop, charity catalogue purchase, Big Issue); Credit/debit card or cheque; Cash gifts (eg collection at work, school, street, pub or place of worship, or sponsoring someone by cash); Direct Debit, standing order or covenant; Fundraising event (eg jumble sale, fetes, charity dinners); Buying a raffle or lottery ticket (not the National Lottery); Payroll giving/regular deduction direct from salary; Membership fees and subscriptions paid to charity; Other methods
} 
However, this small group of large donors cannot explain all the difference in mean monthly donation size. As shown in column III, excluding monthly donations greater than $£ 1,300$ reduces mean monthly donations among CAF account holders to $£ 162.47$, still nearly five times the $£ 33.42$ average in UK Giving. In other words, even setting the very large donors aside, people in the CAF data give disproportionally much more than the random sample in UK Giving.

Table A1: Comparison of monthly donations ( $£$ ), CAF account holders and donors in a random population survey (UK Giving)

\begin{tabular}{lccc}
\hline & UK Giving & II & III \\
& & CAF & CAF $(<\mathbf{\& 1 , 3 3 0})$ \\
\hline Mean & 33.42 & 278.94 & 162.47 \\
$1 \%$ & 0.5 & 5 & 5 \\
$5 \%$ & 1 & 10 & 10 \\
$10 \%$ & 2 & 20 & 20 \\
$25 \%$ & 5 & 35 & 35 \\
Median & 13 & 90 & 82.5 \\
$75 \%$ & 32 & 200 & 200 \\
$90 \%$ & 76 & 500 & 420 \\
$95 \%$ & 121 & 900 & 615 \\
$99 \%$ & 335 & 2,760 & 1066.25 \\
Largest & 1,330 & $1,500,000$ & 1,330 \\
\hline $\mathrm{N}$ & 1,715 & 327,077 & 318,346 \\
\hline
\end{tabular}

Table A2 maps the distribution of giving in the CAF data to the distribution of giving in UK Giving. We form decile boundaries using UK Giving (column I) and then place the CAF account holders into those bins (column II). Column III shows the percentage of total UK Giving done by the UK Giving people in each of the bins. The bottom row shows that just over half of the CAF account-holders would be placed in the top decile of UK Giving donors, and those top decile UK Giving donors give 53.6 per cent of total donations. Similarly, 70.9 per cent of the CAF sample would be placed in the top two deciles, and those two deciles give 69.8 per cent of total donations. Assuming that the giving behaviour of CAF account holders is typical of 
that of donors in these top deciles, then they represent a group of donors whose behaviour drives a large share of total donations in the UK.

Table A2: Comparison of CAF account holders against the distribution of donors in the UK Giving sample

\begin{tabular}{lccc}
\hline $\begin{array}{l}\text { Decile of UK Giving } \\
\text { sample }\end{array}$ & $\begin{array}{c}\text { I } \\
\text { Percentage of UK } \\
\text { Giving sample }\end{array}$ & $\begin{array}{c}\text { II } \\
\text { Percentage of CAF } \\
\text { account-holders }\end{array}$ & $\begin{array}{c}\text { III } \\
\text { Percentage of total } \\
\text { donations, } \\
\text { UK Giving sample }\end{array}$ \\
\hline 1 & $10.0 \%$ & $0.0 \%$ & $0.4 \%$ \\
2 & $10.0 \%$ & $0.1 \%$ & $0.9 \%$ \\
3 & $10.0 \%$ & $1.3 \%$ & $1.5 \%$ \\
4 & $10.0 \%$ & $1.7 \%$ & $2.5 \%$ \\
5 & $10.0 \%$ & $3.2 \%$ & $3.3 \%$ \\
6 & $10.0 \%$ & $4.3 \%$ & $5.0 \%$ \\
7 & $10.0 \%$ & $8.9 \%$ & $6.5 \%$ \\
9 & $10.0 \%$ & $9.5 \%$ & $9.9 \%$ \\
10 & $10.0 \%$ & $19.1 \%$ & $16.2 \%$ \\
\hline
\end{tabular}

\section{Overdrafts and Off-Account}

There are two features of the accounts that might be thought to affect the results. First. individuals can only make donations out of funds that are in their account- there is no overdraft facility. Although top-ups are possible at any time, not being to overdraft would seem likely to bias the findings towards shifting contributions across causes more going to one cause would automatically result in less going to another cause in the absence of a top-up. This makes the observed behavioral response of lift and no shift, if anything, more striking.

Second, we do not observe any off-account donations. However, survey evidence collected in 2009 showed that CAF account holders use their accounts for nearly all their contributions. Furthermore, in a sensitivity analysis presented in Appendix B, we confirm our main results for a sample of regular account users (who give in each of the six years, 2009-2014), who are more likely to use their charity account exclusively. 


\section{Appendix B. Additional results and robustness checks}

In our main specification, we model the dynamics of the response to appeals using a set of indicators for the two weeks before, and the twenty weeks after, the date of the disaster. The coefficients on these weekly indicators capture the difference in donations in the weeks before and after the appeal, compared to a baseline level of donations in all other weeks. For convenience, our main results focus on the averages of these coefficients over the distinct phases of the response period - aftermath, adjustment, settling and return. In this Appendix we present further analysis of whether our approach is sufficient to capture the dynamics of the response to the appeals. We also report additional regression results.

First, weekly indicators for weeks 20-24 after the date of the appeal are not statistically significant, indicating that a twenty-week appeal period (i.e. weeks 019) is long enough to capture deviations in donations from the baseline level.

Table B1, panel $\mathrm{b}$ reports results from estimating a specification that adds five additional weekly indicators, extending into weeks 20-24. The coefficients on these indicators are close to zero and insignificant. Adding the extra indicators changes the definition of the baseline period, but the estimates for weeks $0-4,5-9,10-14$, and $15-19$ are virtually identical to those in our main specification, reported again in panel a for comparison.

Table B1: Estimated response to DEC appeals

\begin{tabular}{lccccc}
\hline & Week 0-4 & Week 5-9 & Week 10-14 & Week 15-19 & Week 20-24 \\
\hline \multicolumn{2}{l}{ a. 20-week disaster period } & & & & \\
DEC-13 & 1.571 & 0.429 & 0.112 & 0.035 & \\
$(£ 10,331)$ & $(0.060)$ & $(0.052)$ & $(0.050)$ & $(0.051)$ & \\
OTHER & 0.100 & -0.062 & -0.045 & -0.026 & \\
$(£ 157,836)$ & $(0.028)$ & $(0.032)$ & $(0.030)$ & $(0.028)$ & \\
\hline b. 25-week disaster period & & & & \\
DEC-13 & 1.575 & 0.431 & 0.116 & 0.038 & 0.030 \\
$(£ 10,769)$ & $(0.061)$ & $(0.053)$ & $(0.051)$ & $(0.051)$ & $(0.056)$ \\
OTHER & 0.104 & -0.061 & -0.041 & -0.022 & 0.028 \\
$(£ 136,232)$ & $(0.028)$ & $(0.032)$ & $(0.030)$ & $(0.028)$ & $(0.034)$ \\
\hline
\end{tabular}

Notes. The table reports the average response (the mean of the estimated weekly coefficients) during different phases of the appeal period, compared to baseline. All regressions (estimated using OLS) include controls for systematic time effects (indicators for day of week, day of month, month, public holidays and major telethons and a linear trend). Robust standard errors in brackets. 


\section{Second, the baseline level of donations is the same after each of the appeals} despite variation in the magnitude of the response. This supports our approach of treating the response to appeals as deviations from a (common) baseline level of donations.

Our test is based on comparing the level of donations across baseline periods after each disaster appeals. We drop all days during the twenty-week post-appeal periods.

We define a set of indicators for separate baseline periods, one after each appeal, starting twenty weeks after the date of the appeal and finishing the day before the next appeal.

Table B2 reports the coefficients on five baseline indicator variables. ${ }^{9}$ The coefficient estimates, ranging from .121 to -.178 , are small in magnitude relative to the response to the DEC appeal in weeks $0-4$ (1.571 and .429; from Table 2 row 1). These coefficients capture differences in donations during each of the subsequent baseline periods relative to an initial baseline which runs from the date our panel data begin (1st June 2009) to the day before the first appeal in our sample ( $3^{\text {rd }}$ October 2009). None of the coefficients is significant, indicating that donations are the same in subsequent baseline periods as in the initial baseline period.

Table B2: Test for differences in donations across separate baseline periods.

Estimated coefficients

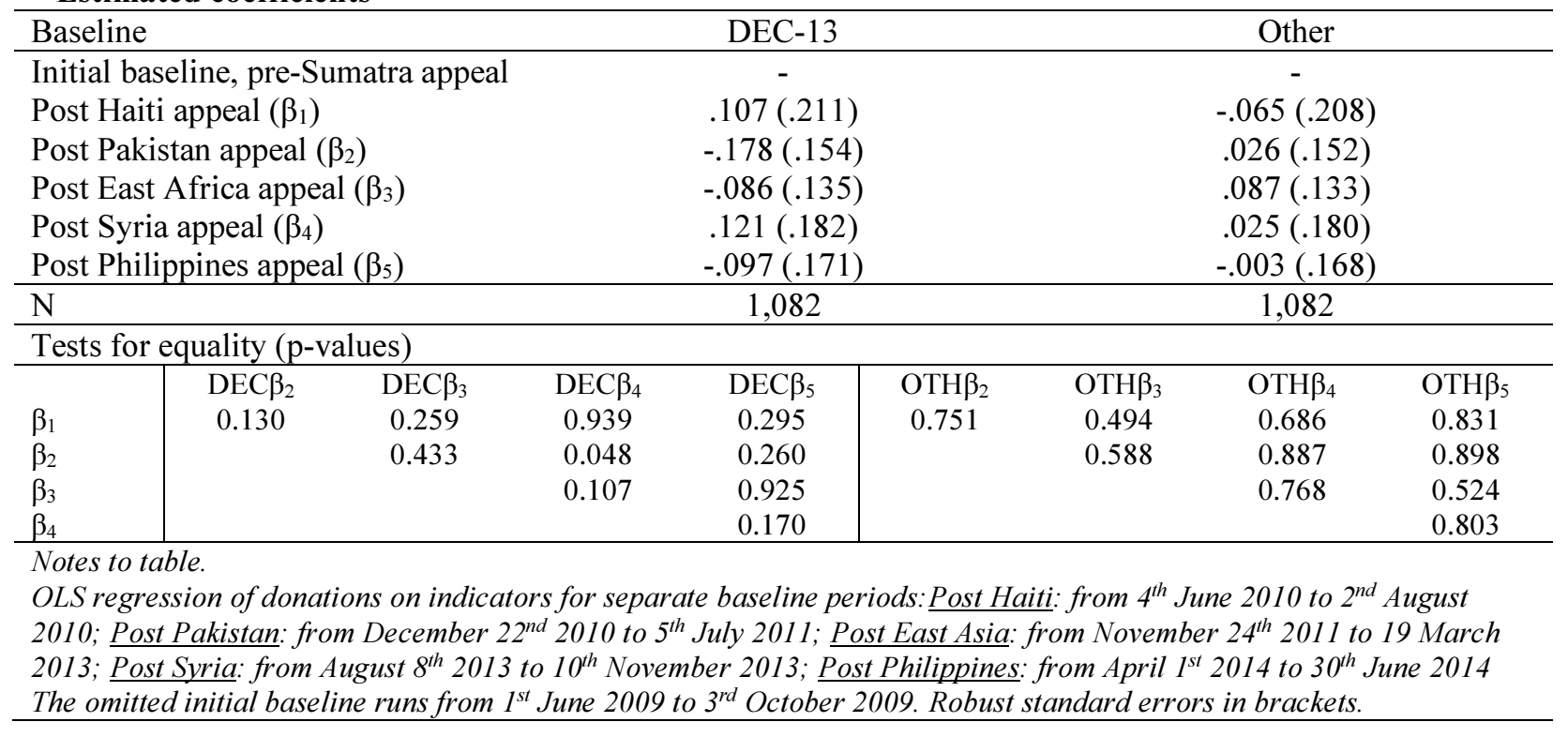

\footnotetext{
${ }^{9}$ There is no baseline period after the Sumatra appeal ( $4^{\text {th }}$ October 2009) because of the short elapsed time before the Haiti appeal (14 January 2010)
} 
However, the initial baseline period is an arbitrary benchmark. It represents the start of our data period, but it is itself the post-appeal period for an earlier DEC appeal. Also relevant therefore is the fact that donations are the same across different subsequent baseline periods. Tests for equality of the coefficients on the five baseline indicator variables show that almost all differences are insignificant: Donations return to the same level in the baseline period after Haiti as in the baseline period after Syria, despite the magnitude of the response to the two DEC appeals being very different.

Third, we test for - and reject - the presence of serial correlation in the residuals from the main specification. This indicates that the dynamic response indicators $\left\{W_{n}\right\}_{\{n=-2\}}^{20}$ are sufficient to capture the dynamics in the disaster periods.

Table B3 presents the serial correlation test. We first estimate the specification of log donations on the dynamic response indicators $\left\{W_{n}\right\}_{\{n=-2\}}^{20}$ and the systematic timebased controls $\theta_{t}^{i}$, form the residuals $\hat{u}_{t}^{i}$; and then estimate an auxiliary regression that is the same as the first specification, but with the additional term $\rho \hat{u}_{t-1}^{i}$. The coefficients in column 3 are the $\hat{\rho}$ coefficients, their standard errors are in parentheses; $p$-values for the test of $\rho=0$ are in square brackets.

Table B3: Serial correlation tests

\begin{tabular}{|c|c|c|c|c|}
\hline \multirow{3}{*}{ Periods } & \multirow{3}{*}{$\begin{array}{l}\text { Controls for } \\
\text { response dynamics } \\
\left\{W_{n}\right\}_{\{n=-2\}}^{20}\end{array}$} & (1) & (2) & (3) \\
\hline & & \multicolumn{3}{|c|}{ Donations } \\
\hline & & DEC-13 & Other & Total \\
\hline $\begin{array}{l}\text { Baseline only } \\
\qquad\left(N_{\text {days }}=1,082\right)\end{array}$ & n.a. & $\begin{array}{l}-.023 \\
(.032) \\
{[.472]}\end{array}$ & $\begin{array}{l}.006 \\
(.032) \\
{[.863]}\end{array}$ & $\begin{array}{l}.002 \\
(.031) \\
{[.962]}\end{array}$ \\
\hline $\begin{array}{l}\text { Post-appeal only } \\
\qquad\left(N_{\text {days }}=800\right)\end{array}$ & no & $\begin{array}{l}.508 \\
(.032) \\
{[.000]}\end{array}$ & $\begin{array}{l}.037 \\
(.038) \\
{[.334]}\end{array}$ & $\begin{array}{l}.173 \\
(.037) \\
{[.000]}\end{array}$ \\
\hline $\begin{array}{l}\text { All periods } \\
\qquad\left(N_{\text {days }}=1,883\right)\end{array}$ & yes & $\begin{array}{l}.037 \\
(.024) \\
{[.133]}\end{array}$ & $\begin{array}{l}-.005 \\
(.025) \\
{[.851]}\end{array}$ & $\begin{array}{l}.016 \\
(.025) \\
{[.519]}\end{array}$ \\
\hline $\begin{array}{l}\text { Votes: Estimated coe, } \\
\text { ull set of controls for } \\
\text { iolidays and major te } \\
\left.\beta_{n}^{i}\right\}_{\{n=-2\}}^{20} \text { that we us } \\
\end{array}$ & $\begin{array}{l}\text { on the lagged residu } \\
\text { natic effects (indicator } \\
\text { s and a linear trend) } \\
\text { apture the response dy }\end{array}$ & $\begin{array}{l}\text { led to a } s p \\
\text { y of week, } \\
\text { ere indica } \\
\text { Robust st } \\
\text { tion }\end{array}$ & $\begin{array}{l}\text { of log don } \\
\text { nth, mont } \\
\text { of coeffic } \\
\text { ors in par }\end{array}$ & \\
\hline
\end{tabular}


Row 1 focuses on just the baseline periods. The $\hat{\rho}=.002$ coefficient [p-value $=$ 0.962] in column (3) indicates that, after allowing for systematic time-based controls $\left(\theta^{i}\right)$, there are no first-order dynamics in daily total donations during the baseline periods. Columns (1) and (2) confirm no first-order dynamics in donations to DEC-13 and Other charities.

Row 2 focuses on the post-appeal periods. The systematic time-based controls $\theta_{t}^{i}$ are included, but the dynamic response indicators $\left\{W_{n}\right\}_{\{n=-2\}}^{20}$ are not. There is strong evidence of serial correlation in log total donations in the weeks that follow the appeals (column 3). Columns (1) and (2) indicate that this dynamic is driven by donations to DEC-13.

Row 3 combines post-appeal and baseline periods and includes the dynamic response indicators, $\left\{W_{n}\right\}_{\{n=-2\}}^{20}$. The $\hat{\rho}=.016$ coefficient $[p$-value $=0.519]$ indicates that, after inclusion of the dynamic response indicators, there is no remaining dynamic in total donations. The coefficients of $.037[\mathrm{p}$-value $=0.133]$ and $-.005[\mathrm{p}$-value $=$ $0.851]$ in columns (1) and (2) show the same for donations to DEC-13 and Other charities. These results indicate that the usual OLS standard errors are correctly specified.

Fourth, we confirm that our main findings are robust to aggregating the data to the week-level, five-week level and twenty-week level.

Our main analysis is based on daily data. This allows us to define week-before and week-after indicators relative to the exact date of the appeal and also to control flexibly for systematic time effects, including those that operate at the daily level, such as public holidays. The test for serial correlation confirms that there are no remaining first-order dynamics in the residuals from this specification, but there may be a concern about lower-frequency serial correlation (e.g. at the weekly level). We therefore re-run our analysis at a higher-level of aggregation to confirm that there is little, if any, distortion in the results from the daily-specification. Table B4, panel a. replicates results from daily data for comparison. The remaining panels (b. - d.) shows results from aggregating data to the week-, five-week- and twenty-week level. Table B4, panel b. presents results from running the regression on weekly-averaged data. As in our main specification, we define week-before and week-after indicators relative to the exact date of the appeal and average across seven-day periods. This 


\section{Additional regression results}

In the body of the paper, we report the average response in $\ln$ (donations) during the four phases of the response period. In this Appendix, we present additional results as follows:

- Table B5 reports the full set of estimated coefficients on the weekly indicators (corresponding to Figure 1).

- Table B6 reports results shedding light on what lies behind the increase in total donations - the results correspond to our main specification but with $\ln$ (number donations) and $\ln ($ mean donation size) as the dependent variable. There is an increase in both the number of donations and mean donation size to DEC-13 in response to the appeal. The time-shifting occurs in the number of donations to other charities, which are below baseline in the adjustment period, but there is an increase in the size of donations to other charities in the immediate aftermath.

- Table B7 reports results corresponding to our main specification for each DEC appeal (with the exception of Sumatra since the response period includes the Haiti appeal) showing that the pattern of responses is not driven by a single appeal.

- Table B8 reports results corresponding to our main specification for CAF donors who make a donation in each of the years, 2009-2014. This addresses any possible concerns that we may miss part of the response that occurs offaccount by focusing on a set of regular donors who are more likely to do their all their giving via their $\mathrm{CAF}$ account.

As in our main specification, all regressions (estimated using OLS) include controls for systematic time effects (indicators for day of week, day of month, month, public holidays and major telethons and a linear trend). Robust standard errors in brackets. 
Table B5: Estimated responses, weekly coefficients

$\underline{\text { Dependent variable }=\operatorname{Ln}(\text { donations })}$

\begin{tabular}{lllll}
\hline & DEC-13 & \multicolumn{3}{l}{ Other } \\
\hline Week -2 & 0.092 & $(0.101)$ & -0.013 & $(0.062)$ \\
Week -1 & 0.202 & $(0.114)$ & 0.050 & $(0.064)$ \\
Week 0 & 2.092 & $(0.161)$ & 0.185 & $(0.058)$ \\
Week 1 & 1.658 & $(0.130)$ & 0.116 & $(0.057)$ \\
Week 2 & 1.532 & $(0.115)$ & 0.199 & $(0.048)$ \\
Week 3 & 1.490 & $(0.106)$ & 0.007 & $(0.073)$ \\
Week 4 & 1.082 & $(0.119)$ & -0.007 & $(0.060)$ \\
Week 5 & 0.809 & $(0.118)$ & -0.014 & $(0.048)$ \\
Week 6 & 0.525 & $(0.110)$ & -0.016 & $(0.071)$ \\
Week 7 & 0.328 & $(0.096)$ & -0.041 & $(0.052)$ \\
Week 8 & 0.171 & $(0.113)$ & -0.158 & $(0.092)$ \\
Week 9 & 0.312 & $(0.097)$ & -0.081 & $(0.061)$ \\
Week 10 & 0.092 & $(0.102)$ & -0.095 & $(0.064)$ \\
Week 11 & 0.251 & $(0.099)$ & -0.090 & $(0.068)$ \\
Week 12 & 0.153 & $(0.108)$ & -0.004 & $(0.069)$ \\
Week 13 & -0.058 & $(0.101)$ & -0.053 & $(0.061)$ \\
Week 14 & 0.122 & $(0.096)$ & 0.016 & $(0.054)$ \\
Week 15 & 0.016 & $(0.137)$ & -0.066 & $(0.080)$ \\
Week 16 & -0.024 & $(0.101)$ & 0.009 & $(0.042)$ \\
Week 17 & -0.023 & $(0.091)$ & -0.128 & $(0.059)$ \\
Week 18 & 0.168 & $(0.101)$ & 0.001 & $(0.052)$ \\
Week 19 & 0.037 & $(0.092)$ & 0.055 & $(0.058)$ \\
\hline
\end{tabular}


Table B6: Estimated responses, alternative outcomes

a. Dependent variable $=\operatorname{Ln}$ (number of donations)

\begin{tabular}{lccccc}
\hline & Aftermath & Adjustment & Settling & Return & Overall \\
& Weeks 0-4 & Weeks 5-9 & Weeks 10-14 & Weeks 15-19 & Weeks 0-19 \\
\hline DEC-13 & 1.080 & 0.193 & 0.020 & 0.031 & 0.331 \\
& $(0.057)$ & $(0.046)$ & $(0.049)$ & $(0.047)$ & $(0.029)$ \\
OTHER & 0.056 & -0.081 & -0.060 & -0.018 & -0.026 \\
& $(0.032)$ & $(0.034)$ & $(0.033)$ & $(0.030)$ & $(0.019)$ \\
\hline
\end{tabular}

b. $\quad$ Dependent variable $=\operatorname{Ln}($ mean donation $)$

\begin{tabular}{lccccc}
\hline & Aftermath & Adjustment & Settling & Return & Overall \\
& Weeks 0-4 & Weeks 5-9 & Weeks 10-14 & Weeks 15-19 & Weeks 0-19 \\
\hline DEC-13 & 0.500 & 0.227 & 0.087 & 0.002 & 0.205 \\
& $(0.023)$ & $(0.029)$ & $(0.026)$ & $(0.024)$ & $(0.016)$ \\
OTHER & 0.040 & 0.019 & 0.014 & -0.008 & 0.016 \\
& $(0.013)$ & $(0.015)$ & $(0.015)$ & $(0.013)$ & $(0.008)$ \\
\hline
\end{tabular}

Table B7: Estimated responses, by appeal

Dependent variable $=\operatorname{Ln}($ donations $)$

\begin{tabular}{lccccc}
\hline & $\begin{array}{c}\text { Aftermath } \\
\text { Weeks 0-4 }\end{array}$ & $\begin{array}{c}\text { Adjustment } \\
\text { Weeks 5-9 }\end{array}$ & $\begin{array}{c}\text { Settling } \\
\text { Weeks 10-14 }\end{array}$ & $\begin{array}{c}\text { Return } \\
\text { Weeks 15-19 }\end{array}$ & $\begin{array}{c}\text { Overall } \\
\text { Weeks 0-19 }\end{array}$ \\
\hline Haiti & & & & & \\
DEC-13 & 2.284 & 0.356 & 0.008 & -0.223 & 0.606 \\
& $(0.277)$ & $(0.253)$ & $(0.198)$ & $(0.244)$ & $(0.091)$ \\
OTHER & 0.492 & 0.010 & -0.128 & -0.179 & 0.049 \\
& $(0.320)$ & $(0.254)$ & $(0.224)$ & $(0.251)$ & $(0.100)$ \\
\hline Pakistan & & & & & \\
DEC-13 & 1.958 & 0.831 & 0.336 & 0.289 & 0.854 \\
& $(0.162)$ & $(0.206)$ & $(0.201)$ & $(0.172)$ & $(0.032)$ \\
OTHER & 0.018 & -0.123 & 0.196 & 0.365 & 0.113 \\
& $(0.222)$ & $(0.234)$ & $(0.206)$ & $(0.184)$ & $(0.112)$ \\
\hline East Africa & & & & & \\
DEC-13 & 1.986 & 0.724 & 0.061 & 0.045 & 0.704 \\
& $(0.154)$ & $(0.236)$ & $(0.196)$ & $(0.187)$ & $(0.105)$ \\
OTHER & 0.238 & -0.216 & -0.076 & 0.087 & -0.045 \\
& $(0.223)$ & $(0.237)$ & $(0.230)$ & $(0.219)$ & $(0.119)$ \\
\hline Syria & & & & & \\
DEC-13 & 1.018 & -0.011 & -0.020 & 0.137 & 0.281 \\
& $(0.173)$ & $(0.211)$ & $(0.223)$ & $(0.201)$ & $(0.108)$ \\
OTHER & 0.004 & -0.181 & -0.010 & -0.002 & -0.047 \\
& $(0.225)$ & $(0.237)$ & $(0.224)$ & $(0.207)$ & $(0.117)$ \\
\hline Philippines & & & & & \\
DEC-13 & 1.826 & 0.474 & -0.133 & -0.060 & 0.527 \\
& $(0.187)$ & $(0.208)$ & $(0.224)$ & $(0.209)$ & $(0.110)$ \\
OTHER & 0.430 & 0.096 & -0.079 & 0.115 & 0.140 \\
& $(0.183)$ & $(0.236)$ & $(0.231)$ & $(0.191)$ & $(0.112)$ \\
\hline
\end{tabular}


Table B8: Estimated responses, regular CAF donors

Dependent variable $=\operatorname{Ln}($ donations $)$

\begin{tabular}{lccccc}
\hline & Aftermath & Adjustment & Settling & $\begin{array}{c}\text { Return } \\
\text { Weeks 0-4 }\end{array}$ & $\begin{array}{c}\text { Overall } \\
\text { Weeks 5-9 }\end{array}$ \\
Weeks 10-14 & Weeks 15-19 & Weeks 0-19 \\
\hline DEC-13 & 1.725 & 0.275 & -0.066 & -0.030 & 0.476 \\
& $(0.100)$ & $(0.119)$ & $(0.116)$ & $(0.099)$ & $(0.064)$ \\
OTHER & 0.053 & -0.097 & -0.028 & -0.014 & -0.021 \\
& $(0.040)$ & $(0.049)$ & $(0.044)$ & $(0.039)$ & $(0.025)$ \\
\hline
\end{tabular}

